\title{
What Do We Learn From Schumpeterian Growth Theory?
}

\section{Citation}

Aghion, Philippe, Ufuk Akcigit, and Peter Howitt. 2013. What do we learn from Schumpeterian growth theory? Working paper, Department of Economics, Harvard University.

\section{Permanent link}

http://nrs.harvard.edu/urn-3:HUL.InstRepos:27755233

\section{Terms of Use}

This article was downloaded from Harvard University's DASH repository, and is made available under the terms and conditions applicable to Other Posted Material, as set forth at http:// nrs.harvard.edu/urn-3:HUL.InstRepos:dash.current.terms-of-use\#LAA

\section{Share Your Story}

The Harvard community has made this article openly available.

Please share how this access benefits you. Submit a story.

\section{Accessibility}




\title{
What Do We Learn From Schumpeterian Growth Theory?*
}

\author{
Philippe Aghion ${ }^{\dagger} \quad$ Ufuk Akcigit ${ }^{\ddagger} \quad$ Peter Howitt S $^{\S}$
}

February 15, 2013

\begin{abstract}
Schumpeterian growth theory has "operationalized" Schumpeter's notion of creative destruction by developing models based on this concept. These models shed light on several aspects of the growth process which could not be properly addressed by alternative theories. In this survey, we focus on four important aspects, namely: $(i)$ the role of competition and market structure; (ii) firm dynamics; ( $i i i)$ the relationship between growth and development with the notion of appropriate growth institutions; $(i v)$ the emergence and impact of long-term technological waves. In each case Schumpeterian growth theory delivers predictions that distinguish it from other growth models and which can be tested using micro data.
\end{abstract}

JEL Classification: O10, O11, O12, O30, O31, O33, O40, O43, O47.

Keywords: Creative destruction, entry, exit, competition, firm dynamics, reallocation, R\&D, industrial policy, technological frontier, Schumpeterian wave, general purpose technology.

${ }^{*}$ This survey builds on a presentation at the Nobel Symposium on Growth and Development (September 2012) and was subsequently presented as the Schumpeter Lecture at the Swedish Entrepreneurship Forum (January 2013). We thank Pontus Braunerhjelm, Mathias Dewatripont, Michael Spence, John Van Reenen, David Warsh, and Fabrizio Zilibotti for helpful comments and encouragements, and Sina Ates, Salome Baslandze, and Felipe Saffie for outstanding editing work.

${ }^{\dagger}$ Harvard University, NBER, and CIFAR.

${ }^{\ddagger}$ University of Pennsylvania and NBER.

$\S$ Brown University and NBER. 


\section{Introduction}

Formal models allow us to make verbal notions operational and confront them with data. The Schumpeterian growth theory surveyed in this paper has "operationalized" Schumpeter's notion of creative destruction -the process by which new innovations replace older technologies, in two ways. First, it has developed models based on creative destruction that shed new light on several aspects of the growth process. Second, it has used data, including rich micro data, to confront the predictions that distinguish it from other growth theories. In the process, the theory has improved our understanding of the underlying sources of growth.

Over the past 25 years, ${ }^{1}$ Schumpeterian growth theory has developed into an integrated framework for understanding not only the macroeconomic structure of growth but also the many microeconomic issues regarding incentives, policies and organizations that interact with growth: who gains and who loses from innovations, and what the net rents from innovation are, these ultimately depend upon characteristics such as property right protection, competition and openness, education, democracy.... and to a different extent in countries or sectors at different stages of development. Moreover, the recent years have witnessed a new generation of Schumpeterian growth models focusing on firm dynamics and reallocation of resources among incumbents and new entrants. ${ }^{2}$ These models are easily estimable using micro firm-level datasets which also brings the rich set of tools from other empirical fields into macroeconomics and endogenous growth.

In this paper, which aims at being accessible to readers with only basic knowledge in economics and is thus largely self-contained, we shall consider four aspects on which Schumpeterian growth theory delivers distinctive predictions. ${ }^{3}$ First, the relationship between growth and industrial organization: faster innovation-led growth is generally associated with higher turnover rates, i.e. higher rates of creation and destruction, of firms and jobs; moreover, competition appears to be positively correlated with growth, and competition policy tends to complement patent policy. Second, the relationship between growth and firm dynamics: small firms exit more frequently than large firms; conditional on survival, small firms grow faster; there is a very strong correlation between firm size and firm age; finally, firm size distribution is highly skewed. Third, the relationship between growth and development with the notion of appropriate institutions: namely, the idea that different types of policies or institutions appear to be growth-enhancing at different stages of development. Our emphasis will be on the relationship between growth and democracy, and on why this relationship appears to be stronger in more frontier economies. Four, the relationship between growth and long-term technological waves: why such waves are associated with an increase in the flow of firm entry and exit; why they may initially generate a productivity slowdown; and why they may increase wage inequality

\footnotetext{
${ }^{1}$ The approach was initiated in the fall of 1987 at MIT, where Philippe Aghion was a first-year assistant professor and Peter Howitt a visiting professor on sabbatical from the University of Western Ontario. During that year they wrote their "model of growth through creative destruction" (see Section 2 below) which came out as Aghion and Howitt (1992). Parallel attempts at developing Schumpeterian growth models, include Segerstrom, Anant and Dinopoulos (1990) and Corriveau (1991).

${ }^{2}$ See Klette and Kortum (2004), Lentz and Mortensen (2008), Akcigit and Kerr (2010), and Acemoglu, Akcigit, Bloom and Kerr (2012)

${ }^{3}$ Thus we are not looking at the aspects or issues that could be addressed by the Schumpeterian model and also by other models, including Romer (1990)'s product variety model (see Aghion and Howitt (1998, 2009)). Grossman and Helpman (1991) were first to point at parallels between the two models, although using a special version of the Schumpeterian model.
} 
both between and within educational groups. In each case we show that Schumpeterian growth theory delivers predictions that distinguishes it from other growth models and which can be tested using micro data.

The paper is organized as follows. Section 2 lays out the basic Schumpeterian model. Section 3 introduces competition and IO into the framework. Section 4 analyzes firm dynamics. Section 5 looks at the relationship between growth and development and in particular at the role of democracy in the growth process. Section 6 discusses technological waves. Section 7 concludes.

A word of caution before we proceed: this paper focuses on the Schumpeterian Growth paradigm and some of its applications, it is not a survey of the existing (endogenous) growth literature. There, we refer the reader to growth textbooks (e.g. Acemoglu (2009), Aghion and Howitt (1998, 2009), Barro and Sala-i-Martin (2003), Galor (2011), Jones and Vollrath (2013), and Weil (2012)).

\section{Schumpeterian growth: basic model}

\subsection{The setup}

The following model borrows directly from the theoretical IO and patent race literatures (see Tirole (1988)). This model is Schumpeterian in that: $(i)$ it is about growth generated by innovations; ( $i i)$ innovations result from entrepreneurial investments that are themselves motivated by the prospects of monopoly rents; (iii) new innovations replace old technologies: in other words, growth involves creative destruction.

Time is continuous and the economy is populated by a continuous mass $L$ of infinitely lived individuals with linear preferences, and which discount the future at rate $\rho .{ }^{4}$ Each individual is endowed with one unit of labor per unit of time, which she can allocate between production and research: in equilibrium, individuals are indifferent between these two activities.

There is a final good, which is also the numeraire. Final good at time $t$ is produced competitively using an intermediate input, namely:

$$
Y_{t}=A_{t} y_{t}^{\alpha}
$$

where $\alpha$ is between zero and one, $y_{t}$ is the amount of intermediate good currently used in the production of final good, and $A_{t}$ is the productivity -or quality- of the currently used intermediate input. ${ }^{5}$

The intermediate good $y$ is in turn produced one for one with labor: that is, one unit flow of labor currently used in manufacturing the intermediate input, produces one unit of intermediate input of frontier quality. Thus $y_{t}$ denotes both, the current production of intermediate input and the flow amount of labor currently employed in manufacturing the intermediate good.

Growth in this model results from innovations that improve the quality of the intermediate input used in the production of the final good. More formally, if the previous state-of-the-art intermediate good was of quality $A$, then a new innovation will introduce a new intermediate input of quality $\gamma A$, where $\gamma>1$. This immediately implies that growth will involve creative

\footnotetext{
${ }^{4}$ The linear preferences (or risk neutrality) assumption implies that the equilibrium interest rate will always be equal to the rate of time preference: $r_{t}=\rho$ (see Aghion and Howitt (2009), Chapter 2).

${ }^{5}$ In what follows we will use the words "productivity" or "quality" indifferently.
} 
destruction, in the sense that Bertrand competition will allow the new innovator to drive the firm producing intermediate good of quality $A$ out of the market, since at the same labor cost the innovator produces a better good than that of incumbent firm. ${ }^{6}$

The innovation technology is directly drawn from the theoretical IO and patent race literatures: namely, if $z_{t}$ units of labor are currently used in $\mathrm{R} \& \mathrm{D}$, then a new innovation arrives during the current unit of time at the (memoriless) Poisson rate $\lambda z_{t}{ }^{7}$ Henceforth we will drop the time index $t$, when it causes no confusion.

\subsection{Solving the model}

\subsubsection{The research arbitrage and labor market clearing equations}

We shall concentrate attention to balanced growth equilibria where the allocation of labor between production $(y)$ and $\mathrm{R} \& \mathrm{D}(z)$ remains constant over time. The growth process is described by two basic equations.

The first is the labor market clearing equation:

$$
L=y+z
$$

reflecting the fact that the total flow of labor supply during any unit of time is fully absorbed between production and $R \& D$ activities (i.e. by the demands for manufacturing and $R \& D$ labor).

The second equation reflects individuals' indifference in equilibrium between engaging in $\mathrm{R} \& \mathrm{D}$ or working in the intermediate good sector. We call it the research arbitrage equation. The remaining part of the analysis consists in spelling out this research arbitrage equation.

More formally, let $w_{k}$ denote the current wage rate conditional on there having already been $k \in \mathbb{Z}_{++}$innovations from time 0 until current time $t$ (since innovation is the only source of change in this model, all other economic variables remain constant during the time interval between two successive innovations). And let $V_{k+1}$ denote the net present value of becoming the next $((k+1)$-th) innovator.

During a small time interval $d t$, between the $k$-th and $(k+1)$-th innovations, an individual faces the following choice. Either she employs her (flow) unit of labor for the current unit of time in manufacturing at the current wage, in which case she gets $w_{t} d t$. Or she devotes her flow unit of labor to $R \& D$, in which case she will innovate during the current time period with

\footnotetext{
${ }^{6}$ Thus overall, growth in the Schumpeterian model involves both, positive and negative externalities. The positive externality is referred to by Aghion and Howitt (1992) as a "knowledge spillover effect": namely, any new innovation raises productivity $A$ forever, i.e the benchmark technology for any subsequent innovation; however the current (private) innovator captures the rents from her innovation only during the time interval until the next innovation occurs. This effect is also featuring in Romer (1990) where it is referred to instead as "non-rivalry plus limited excludability". But in addition, in the Schumpeterian model, any new innovation has a negative externality as it destroys the rents of the previous innovator: following the theoretical IO literature, Aghion and Howitt (1992) refer to this as the "business-stealing effect" of innovation. The welfare analysis in that paper derives sufficient conditions under which the intertemporal spillover effect dominates or is dominated by the business-stealing effect. The equilibrium growth rate under laissez-faire is correspondingly suboptimal or excessive compared to the socially optimal growth rate.

${ }^{7}$ More generally, if $z_{t}$ units of labor are invested in R\&D during the time interval $[t, t+d t]$, the probability of innovation during this time interval is $\lambda z_{t} d t$.
} 
probability $\lambda d t$ and then get $V_{k+1}$, whereas she gets nothing if she does not innovate. ${ }^{8}$ The research arbitrage equation is then simply expressed as:

$$
w_{k}=\lambda V_{k+1} .
$$

The value $V_{k+1}$ is in turn determined by a Bellman equation. We will use Bellman equations repeatedly in this survey, thus it is worth going slowly here. During a small time interval $d t$, a firm collects $\pi_{k+1} d t$ profits. At the end of this interval, it is replaced by a new entrant with probability $\lambda z d t$ through creative destruction, otherwise it preserves the monopoly power and $V_{k+1}$. Hence the value function is written as

$$
V_{k+1}=\pi_{k+1} d t+(1-r d t)\left[\begin{array}{c}
\lambda z d t \times 0 \\
(1-\lambda z d t) \times V_{k+1}
\end{array}\right]
$$

Dividing both sides by $d t$, then taking the limit as $d t \rightarrow 0$ and using the fact that the equilibrium interest rate is equal to the time preference, the Bellman equation for $V_{k+1}$ can be rewritten as:

$$
\rho V_{k+1}=\pi_{k+1}-\lambda z V_{k+1} .
$$

In other words: the annuity value of a new innovation (i.e. its flow value during a unit of time) is equal to the current profit flow $\pi_{k+1}$ minus the expected capital loss $\lambda z V_{k+1}$ due to creative destruction, i.e. to the possible replacement by a subsequent innovator. If innovating gave the innovator access to a permanent profit flow $\pi_{k+1}$, then we know that the value of the corresponding perpetuity would be $\pi_{k+1} / r .{ }^{9}$ However, there is creative destruction at rate $\lambda z$. As a result, we have:

$$
V_{k+1}=\frac{\pi_{k+1}}{\rho+\lambda z}
$$

that is, the value of innovation is equal to the profit flow divided by the risk-adjusted interest rate $\rho+\lambda z$ where the risk is that of being displaced by a new innovator.

\subsubsection{Equilibrium profits, aggregate $R \& D$ and growth}

We solve for equilibrium profits $\pi_{k+1}$ and the equilibrium $\mathrm{R} \& \mathrm{D}$ rate $z$ by backward induction. That is, first, for given productivity of the current intermediate input, we solve for the equilibrium profit flow of the current innovator; then we move one step back and determine the equilibrium $\mathrm{R} \& \mathrm{D}$ using equations $(\mathrm{L})$ and $(\mathrm{R})$.

\footnotetext{
${ }^{8}$ Note that we are implicitly assuming that previous innovators are not candidates for being new innovators. This in fact results from a replacement effect pointed out by Arrow (1962). Namely, an outsider goes from zero to $V_{k+1}$ if she innovates, whereas the previous innovator would go from $V_{k}$ to $V_{k+1}$. Given that the R\&D technology is linear, if outsiders are indifferent betwen innovating and working in manufacturuing then incumbent innovators will strictly prefer to work in manufacturing. Thus new innovations end up being made by outsiders in equilibrium of this model. This feature will be relaxed in the next section.

${ }^{9}$ Indeed, the value of the perpetuity is:

$$
\int_{0}^{\infty} \pi_{k+1} e^{-r t} d t=\frac{\pi_{k+1}}{r} .
$$
}


Equilibrium profits Suppose that $k_{t}$ innovations have already occurred until time $t$, so that the current productivity of the state-of-the-art intermediate input is $A_{k_{t}}=\gamma^{k_{t}}$. Given that the final good production is competitive, the intermediate good monopolist will sell her input at a price equal to its marginal product, namely

$$
p_{k}(y)=\frac{\partial\left(A_{k} y^{\alpha}\right)}{\partial y}=A_{k} \alpha y^{\alpha-1}
$$

This is the inverse demand curve faced by the intermediate good monopolist.

Given that inverse demand curve, the monopolist will choose $y$ to

$$
\pi_{k}=\max _{y}\left\{p_{k}(y) y-w_{k} y\right\} \text { subject to }(2)
$$

since it costs $w_{k} y$ units of numeraire to produce $y$ units of intermediate good. Given the Cobb-Douglas technology for the production of final good, the equilibrium price is a constant markup over the marginal cost $\left(p_{k}=w_{k} / \alpha\right)$ and the profit is simply equal to $\frac{1-\alpha}{\alpha}$ times the wage bill, namely:

$$
\pi_{k}=\frac{1-\alpha}{\alpha} w_{k} y
$$

where $y$ solves (3).

Equilibrium aggregate R\&D Combining (1), (4) and (R), we can rewrite the research arbitrage equation as:

$$
w_{k}=\lambda \frac{\frac{1-\alpha}{\alpha} w_{k+1} y}{\rho+\lambda z} .
$$

Using the labor market clearing condition (L) and the fact that on a balanced growth path all aggregate variables (the final output flow, profits and wages) are multiplied by $\gamma$ each time a new innovation occurs, we can solve (5) for the equilibrium aggregate R\&D $z$ as a function of the parameters of the economy:

$$
z=\frac{\frac{1-\alpha}{\alpha} \gamma L-\frac{\rho}{\lambda}}{1+\frac{1-\alpha}{\alpha} \gamma} .
$$

Clearly it is sufficient to assume that $\frac{1-\alpha}{\alpha} \gamma L>\frac{\rho}{\lambda}$ to ensure positive R\&D in equilibrium. Inspection of (6) delivers a number of important comparative statics. In particular a higher productivity of the $R \& D$ technology as measured by $\lambda$ or higher size of innovations $\gamma$ or a higher size of the population $L$ have a positive effect on aggregate $R \& D$. On the other hand a higher $\alpha$ (which corresponds to the intermediate producer facing a more elastic inverse demand curve and therefore getting lower monopoly rents) or a higher discount rate $\rho$ tend to discourage R\&D.

Equilibrium expected growth Once we have determined the equilibrium aggregate R\&D, it is easy to compute the expected growth rate. First note that during a small time interval $[t, t+d t]$, there will be a successful innovation with probability $\lambda z d t$. Second, the final output is multiplied by $\gamma$ each time a new innovation occurs. Therefore the expected output is simply:

$$
\ln Y_{t+d t}=\lambda z d t \ln \gamma Y_{t}+(1-\lambda z d t) \ln Y_{t}
$$


Subtracting $\ln Y_{t}$ from both sides, dividing through $d t$ and finally taking the limit leads to the following expected growth

$$
\mathbb{E}\left(g_{t}\right)=\lim _{d t \rightarrow 0} \frac{\ln Y_{t+d t}-\ln Y_{t}}{d t}=\lambda z \ln \gamma
$$

which inherits the comparative static properties of $z$ with respect to the parameters $\lambda, \gamma, \alpha, \rho$, and $L$.

A distinct prediction of the model is:

Prediction 0: The turnover rate $\lambda z$ is comonotonic with the growth rate $g$.

\section{Growth meets IO}

Empirical studies (starting with Nickell (1996), Blundell, Griffith and Van Reenen $(1995,1999)$ ) point to a positive correlation between growth and product market competition. Also, the idea that competition - or free entry- should be growth-enhancing, is also prevalent among policy advisers. Yet, non-Schumpeterian growth models cannot account for it: AK models assume perfect competition and therefore have nothing to say on the relationship between competition and growth; and in Romer's product variety model, higher competition amounts to higher degree of substitutability between the horizontally differentiated inputs, which in turn implies lower rents for innovators and therefore lower R\&D incentives and thus lower growth.

In contrast, the Schumpeterian growth paradigm can rationalize the positive correlation between competition and growth found in linear regressions. In addition, it can account for several interesting facts about competition and growth which no other growth theory can explain. ${ }^{10}$ We shall concentrate on three such facts. First, innovation and productivity growth by incumbent firms appear to be stimulated by competition and entry particularly in firms near the technology frontier or in firms that compete "neck-and-neck" with their rivals, less so in firms below the frontier. Second, competition and productivity growth display an inverted-U relationship: starting for an initially low level of competition, higher competition stimulates innovation and growth; starting from a high initial level of competition, higher competition has a less positive or even a negative effect on innovation and productivity growth. Third, patent protection complements product market competition in encouraging $R \& D$ investments and innovation.

Understanding the relationship between competition and growth also helps improve our understanding of the relationship between trade and growth. Indeed there are several dimensions to that relationship. First, the scale effect, whereby liberalizing trade increases the market for successful innovations and therefore the incentives to innovate; this is naturally captured by any innovation-based model of growth including the Schumpeterian growth model. But there is also a competition effect of trade openness, which only the Schumpeterian model can capture. This latter effect appears to have been at work in emerging countries that implemented trade liberalization reforms (for example India in the early 1990s), and it also explains why trade restrictions are more detrimental to growth in more frontier countries (see Section 5 below).

\footnotetext{
${ }^{10}$ See Aghion and Griffith (2006) for a first attempt at synthetizing the theoretical and empirical debates on competition and growth.
} 


\subsection{From leapfrogging to step-by-step innovation ${ }^{11}$}

\subsubsection{The argument}

To reconcile theory with the evidence on productivity growth and product market competition, we replace the leapfrogging assumption of the model in the previous section (where incumbents are systematically overtaken by outside researchers) with a less radical step-by-step assumption: namely, a firm which is currently $m$ steps behind the technological leader in the same sector or industry, must catch up with the leader before becoming a leader itself. This step-by-step assumption can be rationalized by supposing that an innovator acquires tacit knowledge that cannot be duplicated by a rival without engaging in its own $R \& D$ to catch up. This leads to a richer analysis of the interplay between product market competition, innovation, and growth by allowing firms in some sectors to be neck-and-neck. In such sectors, increased product market competition, by making life more difficult for neck-and-neck firms, will encourage them to innovate in order to acquire a lead over their rival in the sector. This we refer to as the escape competition effect. On the other hand, in sectors that are not neck-and-neck, increased product market competition will have a more ambiguous effect on innovation. In particular it will discourage innovation by laggard firms when these do not put much weight on the (more remote) prospect of becoming a leader and instead mainly look at the short-run extra profit from catching up with the leader. This we call the Schumpeterian effect. Finally, the steady state fraction of neck-and-neck sectors will itself depend upon the innovation intensities in neck-and-neck versus unleveled sectors. This we refer to as the composition effect.

\subsubsection{Household}

Time is again continuous and a continuous measure $L$ of individuals work in one of two activities: as production workers and as $\mathrm{R} \& \mathrm{D}$ workers. We assume that the representative household consumes $C_{t}$, has logarithmic instantaneous utility $U\left(C_{t}\right)=\ln C_{t}$ and discounts the future at a rate $\rho>0$. These assumptions deliver the household's Euler equation as $g_{t}=r_{t}-\rho$. All costs in this economy are in terms of labor units. Therefore, consumption of the household is equal to the final good production $C_{t}=Y_{t}$ which is also the resource constraint of this economy.

\subsubsection{A multi-sector production function}

To formalize these various effects, in particular the composition effect, we obviously need a multiplicity of intermediate sectors instead of one as in the previous section. One simple way of extending the Schumpeterian paradigm to a multiplicity of intermediate sectors is, as in Grossman and Helpman (1991), to assume that the final good is produced using a continuum of intermediate inputs, according to the logarithmic production function:

$$
\ln Y_{t}=\int_{0}^{1} \ln y_{j t} d j
$$

Next, we introduce competition by assuming that each sector $j$ is duopolistic with respect to production and research activities. We denote the two duopolists in sector $j$ as $A_{j}$ and $B_{j}$

\footnotetext{
${ }^{11}$ The following model and analysis are based on Aghion, Harris and Vickers (1997), Aghion, Harris, Howitt and Vickers (2001), Aghion, Bloom, Blundell, Griffith and Howitt (2005) and Acemoglu and Akcigit (2012). See also Peretto (1998) for related work.
} 
and assume for simplicity that $y_{j}$ is the sum of the intermediate goods produced by the two duopolists in sector $j$ :

$$
y_{j}=y_{A j}+y_{B j} .
$$

The above logarithmic technology implies that in equilibrium the same amount is spent at any time by final good producers on each basket $y_{j} .{ }^{12}$ We normalize the price of the final good to be 1 . Thus a final good producer chooses each $y_{A j}$ and $y_{B j}$ to maximize $y_{A j}+y_{B j}$ subject to the budget constraint: $p_{A j} y_{A j}+p_{B j} y_{B j}=Y$; that is, she will devote the entire unit expenditure to the least expensive of the two goods.

\subsubsection{Technology and innovation}

Each firm takes the wage rate as given and produces using labor as the only input according to the following linear production function,

$$
y_{i t}=A_{i t} l_{i t}, \quad i \in\{A, B\}
$$

where $l_{j t}$ is the labor employed. Let $k_{i}$ denote the technology level of duopoly firm $i$ in some industry $j$; that is, $A_{i}=\gamma^{k_{i}}, i=A, B$ and $\gamma>1$ is a parameter that measures the size of a leading-edge innovation. Equivalently, it takes $\gamma^{-k_{i}}$ units of labor for firm $i$ to produce one unit of output. Thus the unit costs of production is simply $c_{i}=w \gamma^{-k_{i}}$ which is independent of the quantity produced.

An industry $j$ is thus fully characterized by a pair of integers $\left(k_{j}, m_{j}\right)$ where $k_{j}$ is the leader's technology and $m_{j}$ is the technological gap between the leader and the follower. ${ }^{13}$

For expositional simplicity, we assume that knowledge spillovers between the two firms in any intermediate industry are such that neither firm can get more than one technological level ahead of the other, that is:

$$
m \leq 1
$$

In other words, if a firm already one step ahead innovates, the lagging firm will automatically learn to copy the leader's previous technology and thereby remain only one step behind. Thus, at any point in time, there will be two kinds of intermediate sectors in the economy: $(i)$ leveled or neck-and-neck sectors where both firms are at technological par with one another, and (ii) unleveled sectors, where one firm (the leader) lies one step ahead of its competitor (the laggard or follower) in the same industry. ${ }^{14}$

\footnotetext{
${ }^{12}$ To see this, note that a final good producer will choose the $y_{j}$ 's to maximize $u=\int \ln y_{j} d j$ subject to the budget constraint $\int p_{j} y_{j} d j=E$, where $E$ denotes current expenditures. The first-order condition for this is:
}

$$
\partial u / \partial y_{j}=1 / y_{j}=\lambda p_{j} \text { for all } j
$$

where $\lambda$ is a Lagrange multiplier. Together with the budget constraint this first-order condition implies

$$
p_{j} y_{j}=1 / \lambda=E \text { for all } j .
$$

\footnotetext{
${ }^{13}$ The above logarithmic final good technology together with the linear production cost structure for intermediate goods implies that the equilibrium profit flows of the leader and the follower in an industry depend only upon the technological gap $m$ between the two firms. We will see this below for the case where $m \leq 1$.

${ }^{14}$ Aghion et al (2001) and Acemoglu and Akcigit (2012) analyze the more general case where there is no limit to how far ahead the leader can get.
} 
To complete the description of the model, we just need to specify the innovation technology. Here we simply assume that by spending the $\mathrm{R} \& \mathrm{D}$ cost $\psi(z)=z^{2} / 2$ in units of labor, a leader (or frontier) firm moves one technological step ahead, with probability $z$. We call $z$ the "innovation rate" or "R\&D intensity" of the firm. We assume that a follower firm can move one step ahead with probability $h$, even if it spends nothing on $\mathrm{R} \& \mathrm{D}$, by copying the leader's technology. Thus $z^{2} / 2$ is the $\mathrm{R} \& \mathrm{D}$ cost (in units of labor) of a follower firm moving ahead with probability $z+h$. Let $z_{0}$ denote the R\&D intensity of each firm in a neck-and-neck industry; and let $z_{-1}$ denote the R\&D intensity of a follower firm in an unleveled industry; if $z_{1}$ denotes the $R \& D$ intensity of the leader in an unleveled industry, note that $z_{1}=0$, since our assumption of automatic catch-up means that a leader cannot gain any further advantage by innovating.

\subsection{Equilibrium profits and competition in leveled and unleveled sectors}

We can now determine the equilibrium profits of firms in each type of sector, and link them with product market competition. The final good producer in (7) generates a unit-elastic demand with respect to each variety

$$
y_{j}=\frac{Y}{p_{j}} .
$$

Consider first an unleveled sector where the leader's unit cost is $c$. The leader's monopoly profit is

$$
\begin{aligned}
p_{1} y_{1}-c y_{1} & =\left(1-\frac{c}{p_{1}}\right) Y \\
& =\pi_{1} Y
\end{aligned}
$$

where the first line uses (8) and the second line defines $\pi_{1}$ as the equilibrium profit normalized by the final output $Y$. Note that the monopoly profit is monotonically increasing in the unit price $p_{1}$. However, the monopolist is constrained to setting a price $p_{1} \leq \gamma c$ because $\gamma c$ is the rival's unit cost, so at any higher price the rival could profitably undercut her price and steal all her business. She will therefore choose the maximum possible price $p_{1}=\gamma c$ such that the normalized profit in equilibrium is

$$
\pi_{1}=1-\frac{1}{\gamma}
$$

The laggard in the unleveled sector will be priced out of the market and hence will earn a zero profit:

$$
\pi_{-1}=0
$$

Consider now a leveled (neck-and-neck) sector. If the two firms engaged in open price competition with no collusion, the equilibrium price would fall to the unit cost $c$ of each firm, resulting in zero profit. At the other extreme, if the two firms colluded so effectively as to maximize their joint profits and shared the proceeds, then they would together act like the leader in an unleveled sector, each setting $p=\gamma c$ (we assume that any third firm could compete using the previous best technology, just like the laggard in an unleveled sector), and each earning a normalized profit equal to $\pi_{1} / 2$. 
So in a leveled sector both firms have an incentive to collude. Accordingly we model the degree of product market competition inversely by the degree to which the two firms in a neckand-neck industry are able to collude. (They do not collude when the industry is unleveled because the leader has no interest in sharing her profit.) Specifically, we assume that the normalized profit of a neck-and-neck firm is:

$$
\pi_{0}=(1-\Delta) \pi_{1}, \quad 1 / 2 \leq \Delta \leq 1,
$$

and we parameterize product market competition by $\Delta$, that is, one minus the fraction of a leader's profits that the leveled firm can attain through collusion. Note that $\Delta$ is also the incremental profit of an innovator in a neck-and-neck industry, normalized by the leader's profit.

We next analyze how the equilibrium research intensities $z_{0}$ and $z_{-1}$ of neck-and-neck and backward firms respectively, and consequently the aggregate innovation rate, vary with our measure of competition $\Delta$.

\subsection{The Schumpeterian and escape competition effects}

In balanced growth path, all aggregate variables, including firm values will grow at the rate $g$. For tractability, we will normalize all growing variables by the aggregate output $Y$. Let $V_{m}$ (resp. $V_{-m}$ ) denote the normalized steady-state value of being currently a leader (resp. a follower) in an industry with technological gap $m$, and let $\omega=w / Y$ denote the normalized steady-state wage rate. We have the following Bellman equations: ${ }^{15}$

$$
\begin{aligned}
\rho V_{0} & =\max _{z_{0}}\left\{\pi_{0}+\bar{z}_{0}\left(V_{-1}-V_{0}\right)+z_{0}\left(V_{1}-V_{0}\right)-\omega z_{0}^{2} / 2\right\} \\
\rho V_{-1} & =\max _{z_{-1}}\left\{\pi_{-1}+\left(z_{-1}+h\right)\left(V_{0}-V_{-1}\right)-\omega z_{-1}^{2} / 2\right\} \\
\rho V_{1} & =\pi_{1}+\left(z_{-1}+h\right)\left(V_{0}-V_{1}\right)
\end{aligned}
$$

where $\bar{z}_{0}$ denotes the $R \& D$ intensity of the other firm in a neck-and-neck industry (we focus on a symmetric equilibrium where $\bar{z}_{0}=z_{0}$ ). Note that we already used $z_{1}=0$ in (11).

In words, the growth-adjusted annuity value $\rho V_{0}$ of currently being neck-and-neck is equal to the corresponding profit flow $\pi_{0}$ plus the expected capital gain $z_{0}\left(V_{1}-V_{0}\right)$ of acquiring a lead over the rival plus the expected capital loss $\bar{z}_{0}\left(V_{-1}-V_{0}\right)$ if the rival innovates and thereby becomes the leader, minus the $\mathrm{R} \& \mathrm{D}$ cost $\omega z_{0}^{2} / 2$. Similarly, the annuity value $\rho V_{1}$ of being a technological leader in an unleveled industry is equal to the current profit flow $\pi_{1}$ plus the expected capital loss $z_{-1}\left(V_{0}-V_{1}\right)$ if the leader is being caught up by the laggard (recall that a leader does not invest in $\mathrm{R} \& \mathrm{D}$ in equilibrium); finally, the annuity value $\rho V_{-1}$ of currently being a laggard in an unleveled industry, is equal to the corresponding profit flow $\pi_{-1}$ plus the expected capital gain $\left(z_{-1}+h\right)\left(V_{0}-V_{-1}\right)$ of catching up with the leader, minus the R\&D cost $\omega z_{-1}^{2} / 2$.

Using the fact that $z_{0}$ maximizes (9) and $z_{-1}$ maximizes (10), we have the first order conditions:

$$
\begin{aligned}
\omega z_{0} & =V_{1}-V_{0} \\
\omega z_{-1} & =V_{0}-V_{-1} .
\end{aligned}
$$

\footnotetext{
${ }^{15}$ Note that originally the left-hand-side is written as $r V_{0}-\dot{V}_{0}$. Note that in BGP, $\dot{V}_{0}=g V_{0}$, therefore we get $(r-g) V_{0}$. Finally using household's Euler equation $r-g=\rho$, leads to the Bellman equations in the text.
} 
In Aghion, Harris and Vickers (1997) the model is closed by a labor market clearing equation which determines $\omega$ as a function of the aggregate demand for R\&D plus the aggregate demand for manufacturing labor. Here, for simplicity we shall ignore that equation and take the wage rate $\omega$ as given, normalizing it at $\omega=1$.

Then, using (12) and (13) to eliminate the $V$ 's from the system of equations (9)-(11), we end up with system of two equations in the two unknowns $z_{0}$ and $z_{-1}$ :

$$
\begin{aligned}
z_{0}^{2} / 2+(\rho+h) z_{0}-\left(\pi_{1}-\pi_{0}\right) & =0 \\
z_{-1}^{2} / 2+\left(\rho+z_{0}+h\right) z_{-1}-\left(\pi_{0}-\pi_{-1}\right)-z_{0}^{2} / 2 & =0
\end{aligned}
$$

These equations solve recursively for unique positive values of $z_{0}$ and $z_{-1}$, and we are mainly interested in how equilibrium $R \& D$ intensities are affected by an increase in product market competition $\Delta$. It is straightforward to see from equation (14) and the fact that

$$
\pi_{1}-\pi_{0}=\Delta \pi_{1}
$$

that an increase in $\Delta$ will increase the innovation intensity $z_{0}(\Delta)$ of a neck-and-neck firm. This is the escape competition effect.

Then, plugging $z_{0}(\Delta)$ into (15), we can look at the effect of an increase in competition $\Delta$ on the innovation intensity $z_{-1}$ of a laggard. This effect is ambiguous in general: in particular, for very high $\rho$, the effect is negative as then $z_{-1}$ varies like

$$
\pi_{0}-\pi_{-1}=(1-\Delta) \pi_{1}
$$

In this case the laggard is very impatient and thus looks at its short term net profit flow if it catches up with the leader, which in turn decreases when competition increases. This is the Schumpeterian effect. However, for low values of $\rho$, this effect is counteracted by an anticipated escape competition effect.

Thus the effect of competition on innovation depends on the situation in which a sector is. In unleveled sectors, the Schumpeterian effect is at work even if it does not always dominate. But in leveled (neck-and-neck) sectors, the escape-competition effect is the only effect at work; that is, more competition induces neck-and-neck firms to innovate in order to escape from a situation in which competition constrains profits.

On average, an increase in product market competition will have an ambiguous effect on growth. It induces faster productivity growth in currently neck-an-neck sectors and slower growth in currently unleveled sectors. The overall effect on growth will thus depend on the (steady-state) fraction of leveled versus unleveled sectors. But this steady-state fraction is itself endogenous, since it depends upon equilibrium R\&D intensities in both types of sectors. We proceed to show under which condition this overall effect is an inverted $\mathrm{U}$, and at the same time derive additional predictions for further empirical testing.

\subsubsection{Composition effect and the inverted-U}

In a steady state, the fraction of sectors $\mu_{1}$ that are unleveled is constant, as is the fraction $\mu_{0}=1-\mu_{1}$ of sectors that are leveled. The fraction of unleveled sectors that become leveled each period will be $z_{-1}+h$, so the sectors moving from unleveled to leveled represent the fraction $\left(z_{-1}+h\right) \mu_{1}$ of all sectors. Likewise, the fraction of all sectors moving in the opposite 
direction is $2 z_{0} \mu_{0}$, since each of the two neck-and-neck firms innovates with probability $z_{0}$. In steady state, the fraction of firms moving in one direction must equal the fraction moving in the other direction:

$$
\left(z_{-1}+h\right) \mu_{1}=2 z_{0}\left(1-\mu_{1}\right)
$$

which can be solved for the steady state fraction of unleveled sectors:

$$
\mu_{1}=\frac{2 z_{0}}{z_{-1}+h+2 z_{0}} .
$$

This implies that the aggregate flow of innovations in all sectors is ${ }^{16}$

$$
x=\frac{4\left(z_{-1}+h\right) z_{0}}{z_{-1}+h+2 z_{0}} .
$$

One can show that for $\rho$ large but $h$ not too large, aggregate innovation $x$ follows an inverted-U pattern: it increases with competition $\Delta$ for small enough values of $\Delta$ and decreases for large enough $\Delta$. The inverted- $U$ shape results from the composition effect whereby a change in competition changes the steady-state fraction of sectors that are in the leveled state, where the escape-competition effect dominates, versus the unleveled state, where the Schumpeterian effect dominates. At one extreme, when there is not much product market competition, there is not much incentive for neck-and-neck firms to innovate, and therefore the overall innovation rate will be highest when the sector is unleveled. Thus the industry will be quick to leave the unleveled state (which it does as soon as the laggard innovates) and slow to leave the leveled state (which will not happen until one of the neck-and-neck firms innovates). As a result, the industry will spend most of the time in the leveled state, where the escape-competition effect dominates $\left(z_{0}\right.$ is increasing in $\left.\Delta\right)$. In other words, if the degree of competition is very low to begin with, an increase in competition should result in a faster average innovation rate. At the other extreme, when competition is initially very high, there is little incentive for the laggard in an unleveled state to innovate. Thus the industry will be slow to leave the unleveled state. Meanwhile, the large incremental profit $\pi_{1}-\pi_{0}$ gives firms in the leveled state a relatively large incentive to innovate, so that the industry will be relatively quick to leave the leveled state. As a result, the industry will spend most of the time in the unleveled state where the Schumpeterian effect is the dominant effect. In other words, if the degree of competition is very high to begin with, an increase in competition should result in a slower average innovation rate.

Finally, using the fact that the log of an industry's output rises by the amount $\ln \gamma$ each time the industry completed a two-cycle from neck-and-neck $(m=0)$ to unleveled $(m=1)$ and then back to neck and neck, the average growth rate of final output $g$ is simply equal to the frequency of completed cycles times $\ln \gamma$. But the frequency of completed cycles is itself equal to the fraction of time $\mu_{1}$ spent in the unleveled state times the frequency $\left(z_{-1}+h\right)$ of innovation when in that state. Hence, overall, we have:

$$
g=\mu_{1}\left(z_{-1}+h\right) \ln \gamma=\frac{x}{2} \ln \gamma .
$$

Thus productivity growth follows the same pattern as aggregate innovation with regard to product market competition.

\footnotetext{
${ }^{16} x$ is the sum of the two flows: $\left(z_{-1}+h\right) \mu_{1}+2 z_{0}\left(1-\mu_{1}\right)$. But since the two flows are equal, $x=$ $2\left(z_{-1}+h\right) \mu_{1}$. Substituting for $\mu_{1}$ using (16) yields $x=\frac{4\left(z_{-1}+h\right) z_{0}}{z_{-1}+h+2 z_{0}}$.
} 


\subsection{Predictions}

A first testable prediction is that:

Prediction 1: The relationship between competition and innovation follows an inverted- $U$ pattern and the average technological gap within a sector ( $\mu_{1}$ in the above model) increases with competition.

This prediction is tested by Aghion, Bloom, Blundell, Griffith and Howitt (2005), ABBGH, using a firm-level panel data set of UK firms listed on the London Stock Exchange between 1970 and 1994. Competition is measured by the Lerner Index, or price-cost margin. The Lerner Index is itself defined by operating profits net of depreciation and of the financial cost of capital, divided by sales, averaged across firms within an industry. Figure 1 shows the inverted-U pattern, and it also shows that if we restrict attention to industries above the median degree of neck-and-neckness, the upward sloping part of the inverted $U$ is steeper than if we consider the whole sample of industries. ABBGH also show that the average technological gap across firms within an industry also increases with the degree of competition the industry is subject to.

Prediction 2: More intense competition enhances innovation in "frontier" firms but may discourage it in "non-frontier" firms.

This prediction is tested by Aghion, Blundell, Griffith, Howitt and Prantl (2009). These authors use UK firm level panel data, with over 32,000 annual observations of firms across 166 four-digit industries to look at productivity growth responds differently in firms that are more-than-median close to the world productivity frontier compared to firms that are less-thanmedian close to the technology frontier. Competition is measured by the rate of foreign entry (more precisely, by the change in the share of UK industry employment in foreign-owned plants in the sector) and it is instrumented by policy reforms (deregulation) that were implemented in the UK as part of the implementation of the European Single Market Program. As shown by Figure 2, the upper line depicting how productivity growth responds to entry in more "frontier" firms, is upward sloping, which reflects the escape competition effect at work in neck-and-neck sectors; in contrast, the lower line depicting how productivity growth responds to entry in "less frontier" firms is downward sloping, which reflects the Schumpeterian effect of competition on innovation in laggard firms.

Prediction 3: There is complementarity between patent protection and product market competition in fostering innovation.

In the above model, competition reduces the profit flow $\pi_{0}$ of non-innovating neck-andneck firms whereas patent protection is likely to enhance the profit flow $\pi_{1}$ of an innovating neck-and-neck firm. Both contribute to raising the net profit gain $\left(\pi_{1}-\pi_{0}\right)$ of an innovating neck-and-neck firm, in other word both types of policies tend to enhance the escape competition effect. That competition and patenting should be complementary in enhancing growth rather than mutually exclusive, is at odds with Romer (1990)'s product variety model where competition is always detrimental to innovation and growth (as we discussed above) and for exactly the same reason for why intellectual property rights (IPRs) in form of patent protection are good for innovation: namely competition reduces post innovation rents whereas patent protection increases these rents. ${ }^{17}$ Recent evidence supporting Prediction 3 was provided by

\footnotetext{
${ }^{17}$ Similarly, in Boldrin and Levine (2008), patenting is detrimental to competition and thereby to innovation for the same reason for why competition is good for innovation. To provide support to their analysis the two authors build a growth model where innovation and growth can occur under perfect competition. The model
} 
Qian (2007) and by Aghion, Howitt and Prantl (2012). Qian uses the passage of national pharmaceutical patent law as a natural experiment to test the economic impact of patent. She finds that implementation of patents stimulates innovation mostly in countries with higher market freedom. Similarly, Aghion, Howitt and Prantl look at the effects of implementation of the single market program on R\&D expenditures in countries with different degrees of IPR. Thus they look at 13 manufacturing industries in 15 OECD countries between 1987 and 2005, and find that the implementation of the single market program leads to an increase in $R \& D$ expenditure in countries with strong IPR, not in others. Moreover, the positive response of $\mathrm{R} \& \mathrm{D}$ expenditure to the single market program in strong IPR countries is more pronounced among firms in industries whose equivalent in the US indicate higher patent intensity. This is evidence of a complementarity between IPRs and competition.

Figure 1: Competition vs Innovation

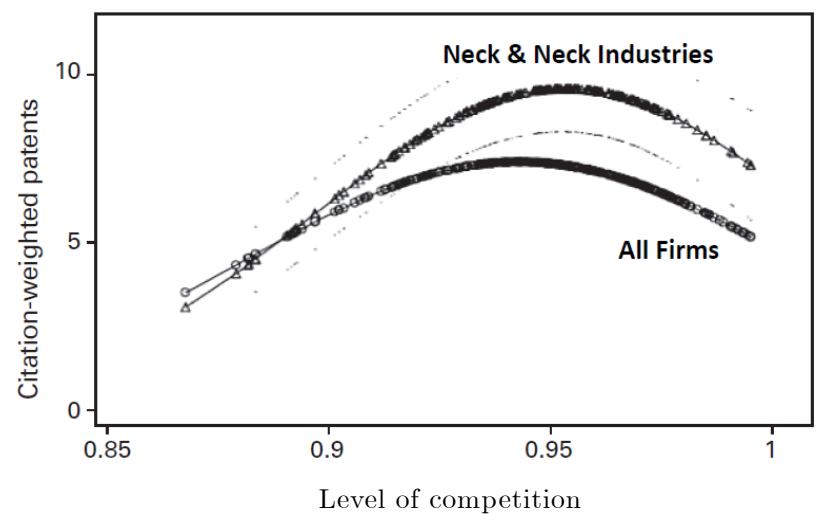

Neck-and-neck split with year and industry effects
Figure 2: Growth vs Entry

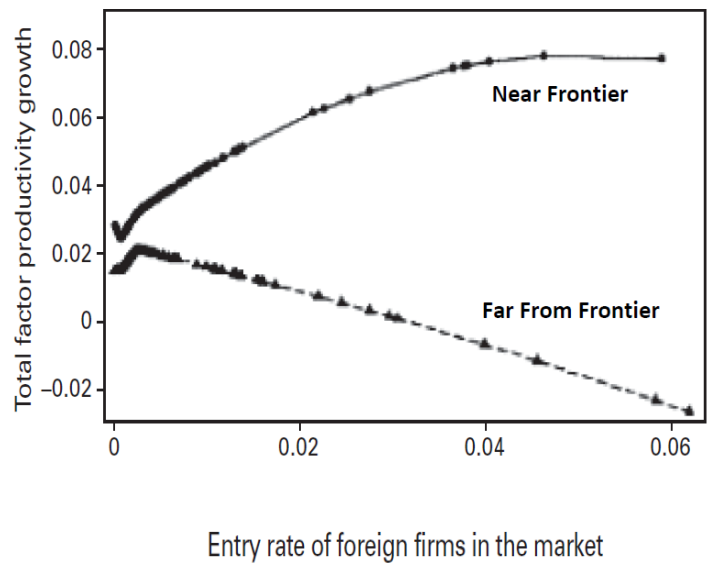

\section{Schumpeterian growth and firm dynamics}

One of the main applications of the Schumpeterian theory has been the study of firm dynamics. The empirical literature has documented various stylized facts using micro firm level data. Some of these facts are: $(i)$ the firm size distribution is highly skewed; $(i i)$ firm size and firm age are highly correlated; (iii) small firms exit more frequently, but the ones that survive tend to grow faster than average growth rate; $(i v)$ a large fraction of $\mathrm{R} \& \mathrm{D}$ in the US is done by incumbents; $(v)$ reallocation of inputs between entrants and incumbents is an important source of productivity growth.

These are some of the well-known empirical facts that non-Schumpeterian growth models cannot account for. In particular, the first four facts listed require a new firm to enter, expand, then shrink over time, and eventually be replaced by new entrants. These and the last fact on the importance of reallocation are all embodied in the Schumpeterian idea of creative destruction.

We will now consider a setup that follows closely the highly influential work by Klette and Kortum (2004). This model will add two elements to the baseline model of Section 2: First, innovations will come from both entrants and incumbents. Second, firms will be defined as a

is then used to argue that monopoly rents and therefore patents are not needed for innovation and growth: on the contrary, patents are detrimental to innovation because they reduce competition. 
collection of production units where successful innovations by incumbents will allow them to expand in product space. Creative destruction will be the central force that drives innovation, invariant firm size distribution and aggregate productivity growth on a balanced growth path.

\subsection{The setup}

Time is again continuous and a continuous measure $L$ of individuals work in one of three activities: $(i)$ as production workers, $l,(i i)$ as R\&D scientists in incumbent firms, $s_{i}$ and (iii) as R\&D scientists in potential entrants, $s_{e}$. The utility function is logarithmic, therefore household's Euler equation is $g_{t}=r_{t}-\rho$. The final good is produced competitively using a combination of intermediate goods according to the following production function

$$
\ln Y_{t}=\int_{0}^{1} \ln y_{j t} d j
$$

where $y_{j}$ is the quantity produced of intermediate $j$. Intermediates are produced monopolistically by the innovator who innovated last within that product line $j$, according to the following linear technology:

$$
y_{j t}=A_{j t} l_{j t}
$$

where $A_{j t}$ is the product-line-specific labor productivity and $l_{j t}$ is the labor employed for production. This implies that the marginal cost of production in $j$ is simply $w_{t} / A_{j t}$ where $w_{t}$ is the wage rate in the economy at time $t$.

A firm in this model is defined as a collection of $n$ production units (product lines) as illustrated in Figure 3. Firms expand in product space through successful innovations.

Figure 3: Example of a Firm

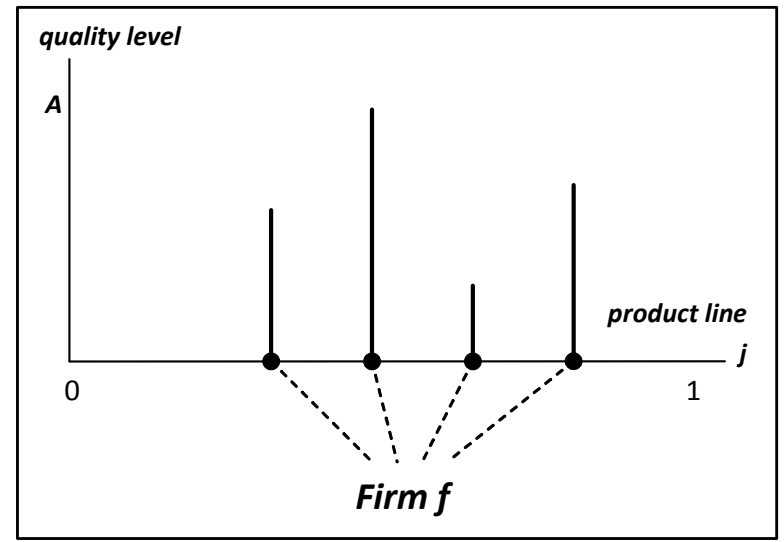

To innovate, firms combine their existing knowledge stock that they accumulated over time $(n)$ with scientists $\left(S_{i}\right)$ according to the following Cobb-Douglas production function

$$
Z_{i}=\left(\frac{S_{i}}{\zeta}\right)^{\frac{1}{\eta}} n^{1-\frac{1}{\eta}}
$$

where $Z_{i}$ is the Poisson innovation flow rate, $\frac{1}{\eta}$ is the elasticity of innovation with respect to scientists and $\zeta$ is a scale parameter. Note that this production function generates the following $R \& D$ cost of innovation

$$
C\left(z_{i}, n\right)=\zeta w n z_{i}^{\eta}
$$


where $z_{i} \equiv Z_{i} / n$ is simply defined as the innovation intensity of the firm. When a firm is successful in its current R\&D investment, it innovates over a random product line $j^{\prime} \in[0,1]$. Then, the productivity in line $j^{\prime}$ increases from $A_{j^{\prime}}$ to $\gamma A_{j^{\prime}}$. The firm becomes the new monopoly producer in line $j^{\prime}$ and thereby increases the number of its production lines to $n+1$. At the same time, each of its $n$ current production lines is subject to the creative destruction $x$ by new entrants and other incumbents. Therefore during a small time interval $d t$, the number of production units of a firm increases to $n+1$ with probability $Z_{i} d t$ and decreases to $n-1$ with probability $n x d t$. A firm that loses all of its product lines exits the economy.

\subsection{Solving the model}

As before, our focus is on a balanced growth path, where all aggregate variables grow at the same rate $g$ (to be determined). We will now proceed in two steps. First we will solve for the static production decision and then turn to the dynamic innovation decision of firms which will determine the equilibrium rate of productivity growth, as well as various firm moments along with the invariant firm size distribution.

\subsubsection{Static production decision}

As in Section 3, final good producer spends the same amount $Y_{t}$ on each variety $j$. As a result, final good production function in (17) generates a unit elastic demand with respect to each variety: $y_{j t}=Y_{t} / p_{j t}$. Combined with the fact that firms in a single product line compete à la Bertrand, this implies that a monopolist with marginal cost $w_{t} / A_{j t}$ will follow limit pricing by setting its price equal to the marginal cost of the previous innovator $p_{j t}=\gamma w_{t} / A_{j t}$. The resulting equilibrium quantity and profit in product line $j$ are:

$$
y_{j t}=\frac{A_{j t} Y_{t}}{\gamma w_{t}} \text { and } \pi_{j t}=\pi Y_{t} .
$$

where $\pi \equiv \frac{\gamma-1}{\gamma}$. Note that profits are constant across product lines, which will significantly simplify the aggregation up to the firm level. Note also that the demand for production workers in each line is simply $Y_{t} /\left(\gamma w_{t}\right)$.

\subsubsection{Dynamic innovation decision}

Next we turn to the innovation decision of the firms. The stock-market value of an $n$-product firm $V_{t}(n)$ at date $t$, satisfies the Bellman equation:

$$
r V_{t}(n)-\dot{V}_{t}(n)=\max _{z_{i} \geq 0}\left\{\begin{array}{c}
n \pi_{t}-w_{t} \zeta n z_{i}^{\eta} \\
+n z_{i}\left[V_{t}(n+1)-V_{t}(n)\right] \\
+n x\left[V_{t}(n-1)-V_{t}(n)\right]
\end{array}\right\} .
$$

The intuition behind this expression is as follows. The firm collects a total of $n \pi_{t}$ profits from $n$ product lines and invests in total $w_{t} \zeta n z_{i}^{\eta}$ in $\mathrm{R} \& \mathrm{D}$. As a result, it innovates at the flow rate $Z_{i} \equiv n z_{i}$ in which case it gains $V_{t}(n+1)-V_{t}(n)$. In addition, the firm loses each of its product lines through creative destruction at the rate $x$, which means that a production line will be lost overall at a rate $n x$, leading to a loss of $V_{t}(n)-V_{t}(n-1)$. It is a straightforward exercise 
to show that the value function in (20) is linear in the number of product lines $n$ and also proportional to aggregate output $Y_{t}$, with the form:

$$
V_{t}(n)=n v Y_{t}
$$

In this expression $v=V_{t}(n) / n Y_{t}$ is simply the average normalized value of a production unit which is endogenously determined as

$$
v=\frac{\pi-\zeta \omega z_{i}^{\eta}}{\rho+x-z_{i}}
$$

Note that this expression uses the Euler equation $\rho=r-g$ and that labor share is defined as $\omega \equiv w_{t} / Y_{t}$, which is constant in balanced growth path. In the absence of incumbent innovation, i.e. $z_{i}=0$, this value is equivalent to the baseline model (1). The fact that incumbents can innovate modifies the baseline value in two opposite directions: First the cost R\&D investment is subtracted from the gross profit which lowers the net instantaneous return $\pi-\zeta \omega z_{i}^{\eta}$. However, each product line comes with an "R\&D option value", that is having one more production unit increases the $R \& D$ capacity of the firm as in (18) and therefore the firm value.

The equilibrium innovation decision of an incumbent is simply found through the first-order condition of (20)

$$
z_{i}=\left(\frac{v}{\eta \zeta \omega}\right)^{\frac{1}{\eta-1}}
$$

As expected, innovation intensity is increasing in the value of innovation $v$ and decreasing in the labor cost $\omega$.

\subsubsection{Free entry}

We consider a mass of entrants that produce one unit of innovation by hiring $\psi$ number of scientists. When a new entrant is successful, it innovates over a random product line by improving its productivity by $\gamma>1$. It then starts out as a single product firm. Let us denote the entry rate by $z_{e}$. The free-entry condition equates the value of a new entry $V_{t}(1)$ to the cost of innovation $\psi w_{t}$ such that

$$
v=\omega \psi \text {. }
$$

Recall that the rate of creative destruction is simply the entry rate plus an incumbent's innovation intensity, i.e., $x=z_{i}+z_{e}$. Using this fact, together with (21), (22) and (23) delivers the equilibrium entry rate and incumbent innovation intensity:

$$
z_{e}=\frac{\pi}{\omega \psi}-\frac{1}{\eta}\left(\frac{\psi}{\eta \zeta}\right)^{\frac{1}{\eta-1}}-\rho \text { and } z_{i}=\left(\frac{\psi}{\eta \zeta}\right)^{\frac{1}{\eta-1}}
$$

\subsubsection{Labor market clearing}

Now we are ready to close the model by imposing the labor market clearing condition. The equilibrium labor share $\omega$ equates the supply of labor $L$ to the sum of aggregate labor demand coming from $(i)$ production, $(\gamma \omega)^{-1},(i i)$ incumbent $\operatorname{R} \& \mathrm{D}, \zeta\left(\frac{\psi}{\eta \zeta}\right)^{\frac{\eta}{\eta-1}}$, and $(i i i)$ outside 
entrants, $\frac{\pi}{\omega}-\zeta\left(\frac{\psi}{\eta \zeta}\right)^{\frac{\eta}{\eta-1}}-\psi \rho$. The resulting labor share is

$$
\omega=\frac{w_{t}}{Y_{t}}=\frac{1}{L+\rho \psi}
$$

\subsection{Equilibrium growth rate}

In this model, innovation takes place by both incumbents and entrants at the total rate of $x=z_{i}+z_{e}$. Hence the equilibrium growth rate is

$$
\begin{aligned}
g & =x \ln \gamma \\
& =\left[\left(\frac{\gamma-1}{\gamma}\right) \frac{L}{\psi}+\left(\frac{\eta-1}{\eta}\right)\left(\frac{\psi}{\eta \zeta}\right)^{\frac{1}{\eta-1}}-\frac{\rho}{\gamma}\right] \ln \gamma
\end{aligned}
$$

In addition to the standard effects, such as the growth rate increasing in the size of innovation and decreasing in the discount rate, this model generates an interesting non-linear relationship between entry cost $\psi$ and growth. An increase in the entry cost reduces the entry rate and therefore has a negative effect on equilibrium growth. However, this effect also frees up those scientists that used to be employed by outside entrants and reallocates them to incumbents, hence increasing innovation by incumbents and growth. This is an interesting trade-off for industrial policy. In a recent work, Acemoglu, Akcigit, Bloom and Kerr (2012) analyze the effects of various industrial policies on equilibrium productivity growth, including entry subsidy and incumbent R\&D subsidy, in an enriched version of the above framework.

\subsection{Predictions}

Now we go back to the initial list of predictions and discuss how they are captured by the above model.

Prediction 1: The size distribution of firms is highly skewed.

In this model, firm size is summarized by the number of product lines of a firm. Let us denote by $\mu_{n}$ the fraction of firms that have $n$ products. The invariant distribution $\mu_{n}$ is found by equating the inflows into state $n$ to the outflows from it:

$$
\begin{aligned}
\mu_{1} x & =z_{e} \\
\left(z_{i}+x\right) \mu_{1} & =\mu_{2} 2 x+z_{e} \\
\left(z_{i}+x\right) n \mu_{n} & =\mu_{n+1}(n+1) x+\mu_{n-1}(n-1) z_{i} \text { for } n \geq 2
\end{aligned}
$$

The first line equates exits to entry. The left-hand side of the second line consists of outflows from being a 1-product firm which happens when a 1-product firm innovates itself and becomes a 2-product firm or is replaced by another firm at the rate $x$. The right-hand side is the sum of the inflows coming from 2-product firms or from outsiders. The third line generalizes the second line to $n$-product firms. The resulting firm size distribution is geometric

$$
\mu_{n}\left(z_{e} / z_{i}\right)=\frac{z_{e} / z_{i}}{\left(1+z_{e} / z_{i}\right)^{n} n}
$$


and highly skewed as shown in a vast empirical literature (Simon and Bonini (1958), Ijiri and Simon (1977), Schmalensee (1989), Stanley et al. (1995), Axtell (2001) and Rossi-Hansberg and Wright (2007)).

Figure 4: Firm Size Distribution

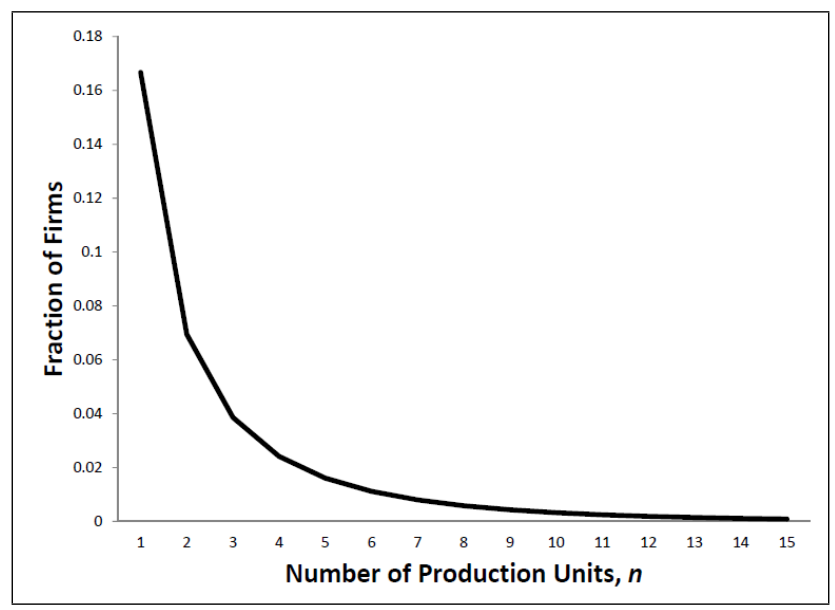

Several alternative Schumpeterian models have been proposed after Klette and Kortum (2004) that feature invariant firm size distributions with a Pareto tail (See Acemoglu and Cao (2011) for an example and a discussion of the literature.)

Prediction 2: Firm size and firm age is positively correlated.

In the current model, firms are born with a size of 1 . It requires subsequent successes for firms to grow in size which naturally produces a positive correlation between size and age. This regularity has been documented extensively in the literature. (For recent discussions and additional references see Haltiwanger, Jarmin and Miranda (2010) and Akcigit and Kerr (2010))

Prediction 3: Small firms exit more frequently. The ones that survive tend to grow faster than average.

In the above model, firm exit happens through the loss of product lines. Conditional on not producing a new innovation, a firm's probability of loosing all of its product lines and exiting within a period is $(x \Delta t)^{n}$ which decreases in $n$. Clearly it becomes much more difficult for a firm to exit when it expands in product space.

The facts that small firms exit more frequently and grow faster conditional on survival have been widely documented in the literature (for early work, see Birch (1981,1987), Davis, Haltiwanger and Schuh (1996). For more recent work on this, see Haltiwanger, Jarmin and Miranda (2010), Akcigit and Kerr (2010), Neumark, Wall and Zhang (2008)).

Prediction 4: A large fraction of $R \mathscr{E} D$ is done by incumbents.

There is an extensive literature that studies R\&D investment and patenting behavior of existing firms in the US (see for instance, among many others, Acs and Audretsch (1988, 1991), Griliches (1990), Hall, Jaffe, and Trajtenberg (2001), Cohen (1995), Cohen and Klepper (1996). In particular, Freeman (1982), Pennings and Buitendam (1987), Tushman and Anderson (1986), Scherer (1984) and Akcigit and Kerr (2010) show that large incumbents focus on improving the existing technologies whereas small new entrants focus on innovating with new radical products or technologies. Similarly, Akcigit, Hanley and Serrano-Velarde (2012) 
provides empirical evidence on French firms showing that large incumbents with a broad technological spectrum account for most of the private basic research investment.

On the theory side, Akcigit and Kerr (2010), Acemoglu and Cao (2011) and Acemoglu, Akcigit, Hanley and Kerr (2012) have also provided alternative Schumpeterian models that capture this fact.

Prediction 5: Both entrants and incumbents innovate. Moreover the reallocation of resources among incumbents as well as from incumbents to new entrants are the major sources of productivity growth.

A central feature of this model is that both incumbents and entrants innovate and contribute to productivity growth. New entrants account for

$$
\frac{z_{e}}{z_{e}+z_{i}}=1-\left[\left(\left(\frac{\gamma-1}{\gamma}\right) \frac{L}{\psi}-\frac{\rho}{\gamma}\right)\left(\frac{\eta \zeta}{\psi}\right)^{\frac{1}{\eta-1}}+\frac{\eta-1}{\eta}\right]^{-1}
$$

percent of innovations in any given period. Bartelsman and Doms (2000) and Foster, Haltiwanger and Krizan (2001) have shown that $25 \%$ of productivity growth in the US is accounted for by new entry and the remaining $75 \%$ by continuing plants. Moreover Foster, Haltiwanger and Krizan (2001 and 2006) have shown that reallocation of resources through entry and exit, accounts for around $50 \%$ of manufacturing and $90 \%$ of US retail productivity growth. In a recently growing cross-country literature, Hsieh and Klenow (2009, 2012), Bartelsman, Haltiwanger and Scarpetta (2009) and Syverson (2011) describe how variations in reallocation across countries explain differences in productivity levels. Lentz and Mortensen (2008) and Acemoglu, Akcigit, Bloom and Kerr (2012) estimate variants of the baseline Klette and Kortum (2004) to quantify the importance of reallocation and study the impacts of industrial policy on reallocation and productivity growth.

\section{Growth meets development}

In this section, we argue that Schumpeterian growth theory helps bridge the gap between growth and development economics, by offering a simple framework to capture the idea that growth-enhancing policies or institutions may vary with a country's level of technological development. In particular we will look at the role of democracy in the growth process, arguing that democracy matters for growth to a larger extent in more advanced economies.

\subsection{Innovation versus imitation and the notion of appropriate institution}

Innovations in one sector or one country often build on knowledge that was created by innovations in another sector or country. The process of diffusion, or technology spillover, is an important factor behind cross-country convergence. Howitt (2000) showed how this can lead to cross-country conditional convergence of growth rates in Schumpeterian growth models. Specifically, a country that starts far behind the world technology frontier can grow faster than one close to the frontier because the former country will make a larger technological advance every time one of its sectors catches up to the global frontier. In Gerschenkron's (1962) terms, countries far from the frontier enjoy an "advantage of backwardness." This advantage implies that in the long run a country with a low rate of innovation will fall behind the frontier, 
but will grow at the same rate as the frontier; as they fall further behind, the advantage of backwardness eventually stabilizes the gap that separates them from the frontier.

These same considerations imply that policies and institutions that are appropriate for countries close to the global technology frontier are often different from those that are appropriate for non-frontier countries, because those policies and institutions that help a country to copy, adapt and implement leading-edge technologies are not necessarily the same as those that help it to make leading-edge innovations. The idea of appropriate institutions was to be developed more systematically by Acemoglu, Aghion and Zilibotti (2006), henceforth AAZ, and it underlies more recent work, in particular Acemoglu and Robinson's best-selling book "Why Nations Fail" (Acemoglu and Robinson (2012)), where the authors rely on a rich set of country studies to argue that sustained growth requires creative destruction and therefore is not sustainable in countries with "extractive institutions".

A particularly direct and simpler way to formalize the idea of appropriate growth policy, is to move for a moment from continuous to discrete time. Following AAZ and more remotely Nelson and Phelps (1966), let $A_{t}$ denote the current average productivity in the domestic country, and $\bar{A}_{t}$ denote the current (world) frontier productivity. Then, think of innovation as multiplying productivity by factor $\gamma$, and of imitation as catching-up with the frontier technology.

Then, if the fraction $\mu_{n}$ of sectors innovates and the fraction $\mu_{m}$ imitates, we have:

$$
A_{t+1}-A_{t}=\mu_{n}(\gamma-1) A_{t}+\mu_{m}\left(\bar{A}_{t}-A_{t}\right)
$$

This in turn implies that productivity growth hinges upon the country's degree of "frontierness", i.e. its "proximity" $a_{t}=A_{t} / \bar{A}_{t}$ to the world frontier, namely:

$$
g_{t}=\frac{A_{t+1}-A_{t}}{A_{t}}=\mu_{n}(\gamma-1)+\mu_{m}\left(a_{t}^{-1}-1\right)
$$

In particular:

Prediction 1: The closer to the frontier an economy is, that is, the closer to one the proximity variable $a_{t}$ is, the more is growth driven by "innovation-enhancing" rather than "imitation-enhancing" policies or institutions.

\subsection{Further evidence on appropriate growth policies and institutions}

In Section 3 above we already mentioned some recent evidence to the prediction that competition and free-entry should be more growth-enhancing. Using a cross-country panel of more than 100 countries over the 1960-2000 period, AAZ regress the average growth rate on a country's distance to the US frontier (measured by the ratio of GDP per capita in that country to per-capita GDP in the US) at the beginning of the period. Then, they split the sample of countries in two groups, corresponding respectively to countries that are more open than the median and to countries that are less open than the median. The prediction is:

Prediction 2: Average growth should decrease more rapidly as a country approaches the world frontier when openness is low.

To measure openness one can use imports plus exports divided by aggregate GDP. But this measure suffers from obvious endogeneity problems: in particular, exports and imports 
are likely to be influenced by domestic growth. To deal with endogeneity problem, Frankel and Romer (1999) construct a more exogenous measure of openness which relies on exogenous characteristics such as land area, common borders, geographical distance, population, etc., and it is this measure that AAZ use to measure openness in the following figures.

\section{Figure 5: Growth, Openness and Distance to Frontier}
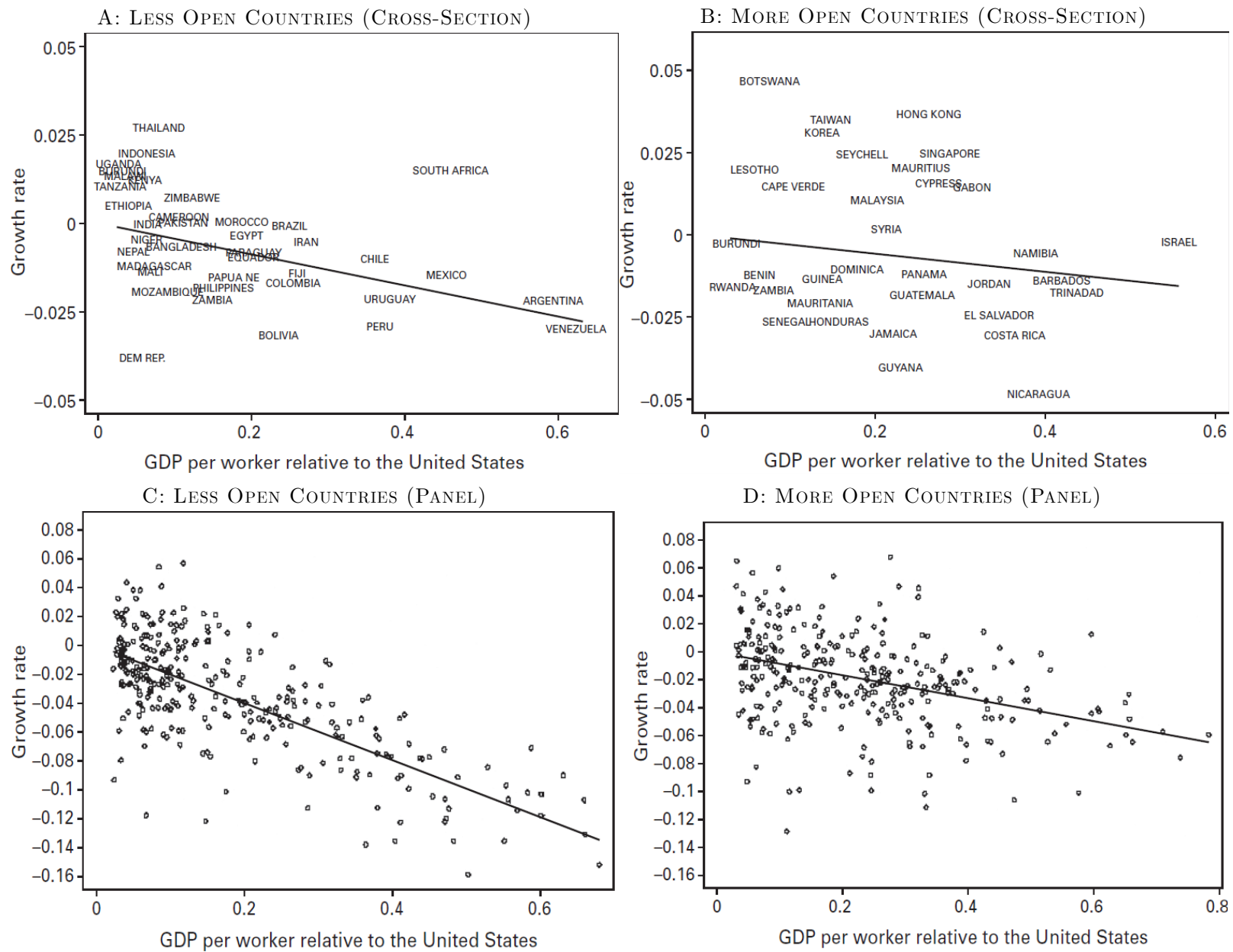

Figures $5 A$ and $5 B$ below show the cross-sectional regressions: here, average growth over the whole 1960-2000 period is regressed over the country's distance to the world technology frontier in 1965, respectively for more open and less open countries. A country's distance to the frontier is measured by the ratio between the log of this country's level of per capita GDP and the maximum of the logs of per capita GDP across all countries (which corresponds to the log of per capita GDP in the US). ${ }^{18}$

Figures $5 C$ and $5 D$ show the results of panel regressions where AAZ decompose the period 1960-2000 in five year subperiods and then for each subperiod AAZ regress average growth

\footnotetext{
${ }^{18}$ That the regression lines should all be downward sloping, reflects that the fact that countries farther below the world technology frontier achieve bigger technological leaps whenever they successfully catch up with the frontier (this is the "advantage of backwardness" we were mentioning above). More formally, for given $\mu_{n}$ and $\mu_{m}, g_{t}=\mu_{n}(\gamma-1)+\mu_{m}\left(a_{t}^{-1}-1\right)$ is decreasing in $a_{t}$.
} 
over the period on distance to frontier at the beginning of the subperiod, respectively for more open and less open countries. These latter regressions control for country fixed effects. In both, cross-sectional and panel regressions we see that while a low degree of openness does not appear to be detrimental to growth in countries far below the world frontier, it becomes increasingly detrimental to growth as the country approaches the frontier.

AAZ repeat the same exercise using entry costs faced by new firms instead of openness. The prediction is:

Prediction 3: High entry barriers become increasingly detrimental to growth as the country approaches the frontier.

Entry costs in turn are measured by the number of days to create a new firm in the various countries (see Djankov et al (2002)). Here, the country sample is split between countries with high barriers relative to the median and countries with low barriers relative to the median. Figures $6 A$ and $6 B$ show the cross-sectional regressions, respectively for low and high barrier countries, whereas Figures $6 C$ and $6 D$ show the panel regressions for the same two subgroups of countries. Both types of regressions show that while high entry barriers do not appear to be detrimental to growth in countries far below the world frontier, they indeed become increasingly detrimental to growth as the country approaches the frontier.

\section{Figure 6: Growth, Entry and Distance to Frontier}

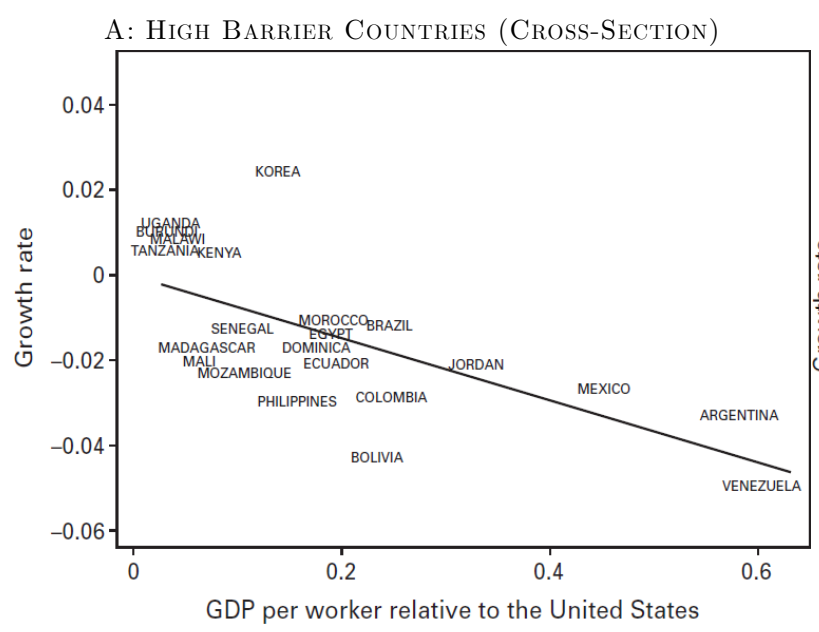

B: Low Barrier Countries (Cross-Section)
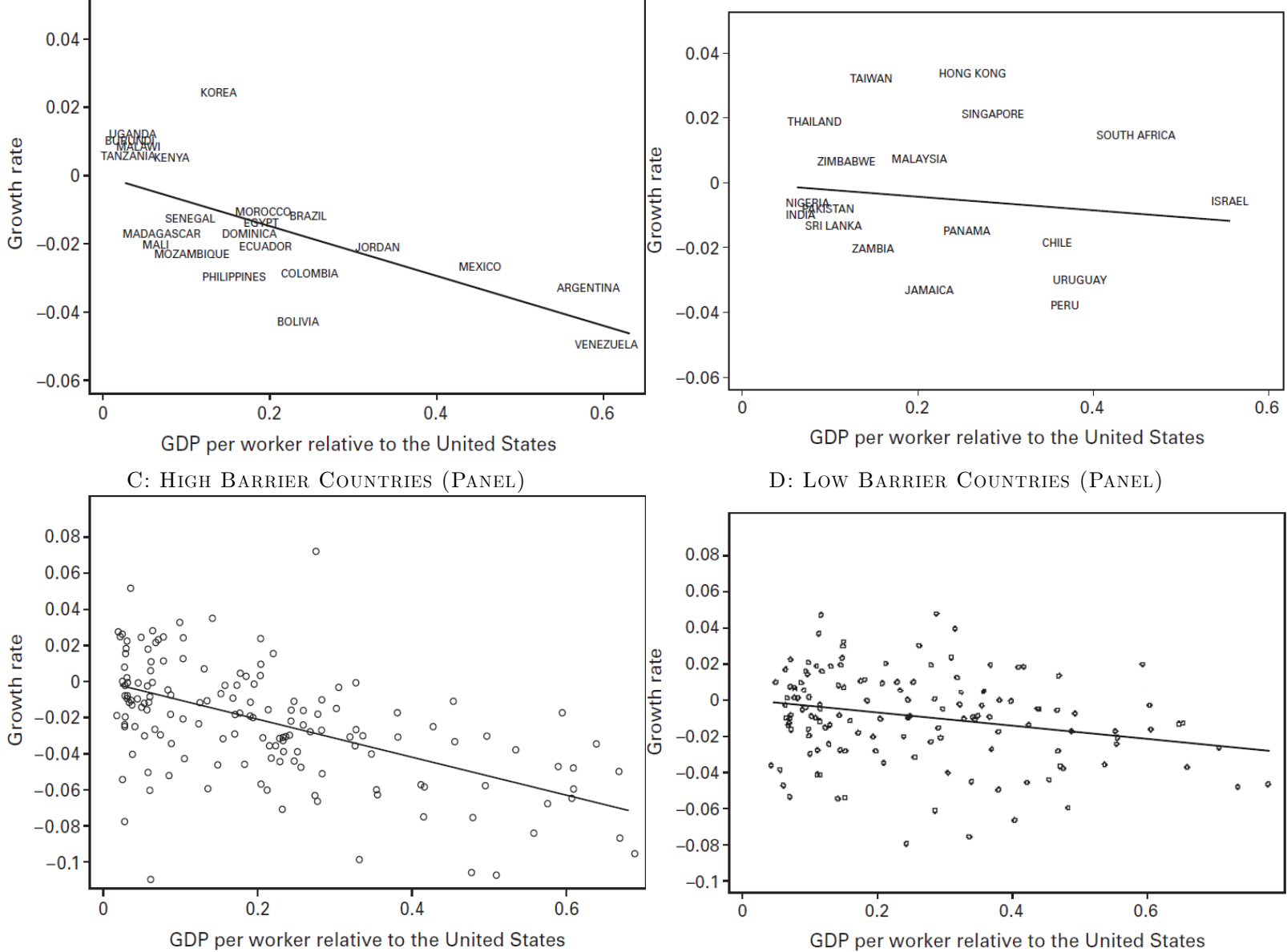

D: Low Barrier Countries (Panel)

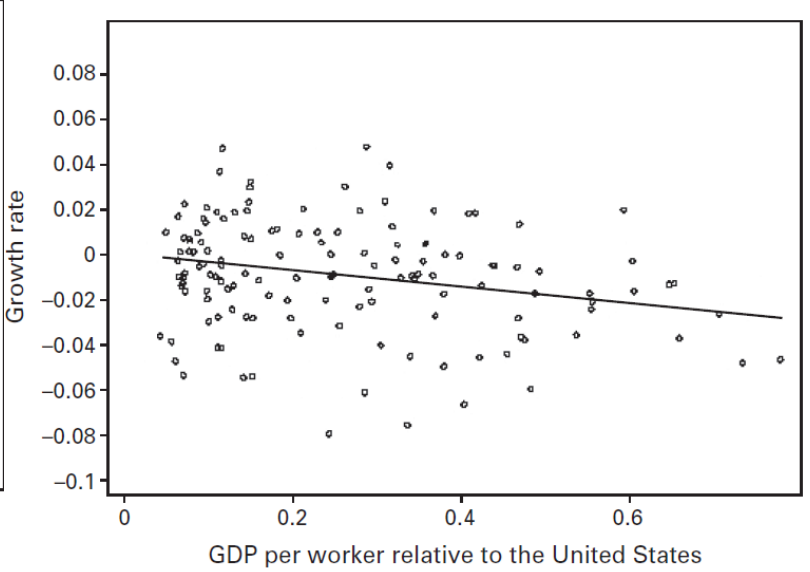


These two empirical exercises point to the importance of interacting institutions or policies with technological variables in growth regressions: openness is particularly growth-enhancing in countries that are closer to the technological frontier; entry is more growth-enhancing in countries or sectors that are closer to the technological frontier; below we will see that higher (in particular, graduate) education tends to be more growth-enhancing in countries or in US states that are closer to the technological frontier, whereas primary-secondary (possibly undergraduate) education tends to be more growth enhancing in countries or in US states that are farther below the frontier.

A third piece of evidence is provided by Aghion, Boustan, Hoxby and Vandenbussche (2009) who use cross-US-states panel data to look at how spending on various levels of education matter differently for growth across US states with different levels of frontierness as measured by their average productivity compared to frontier-state (Californian) productivity. The solid black bars do not factor in the mobility of workers across US states whereas the grey bars do. The more frontier a country or region is, the more its growth relies on frontier innovation and therefore our prediction is:

Prediction 4: The more frontier an economy is, the more growth in this economy relies on research education.

As shown in the figure below, research type education is always more growth-enhancing in states that are more frontier, whereas a bigger emphasis on two year colleges is more growthenhancing in US states that are farther below the productivity frontier. This is not surprising: Vandenbussche, Aghion and Meghir (2006) obtain similar conclusions using cross-country panel data, namely that tertiary education is more positively correlated with productivity growth in countries that are closer to the world technology frontier.

Figure 7: Growth, Education and Distance to Frontier

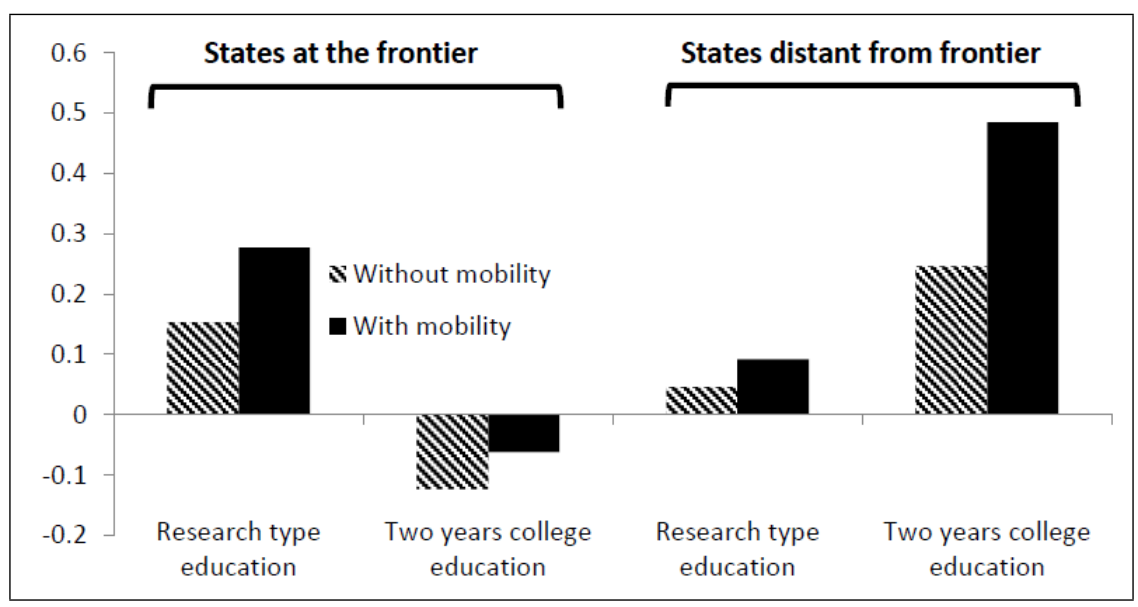

\subsection{Political economy of creative destruction}

Does democracy enhance or hamper economic growth? One may think of various channels whereby democracy should affect per capita GDP growth. A first channel is that democracy pushes for more redistribution from rich to poor, and that redistribution in turn affects growth. Thus Persson and Tabellini (1994) and Alesina and Rodrik (1994) analyze the relationship between inequality, democratic voting, and growth. They develop models in which 
redistribution from rich to poor is detrimental to growth as it discourages capital accumulation. More inequality is then also detrimental to growth because it results in the median voter becoming poorer and therefore demanding more redistribution. A second channel, which we explore in this section, is Schumpeterian: namely, democracy reduces the scope for expropriating successful innovators or for incumbents to prevent new entry by using political pressure or bribes: in other words, democracy facilitates creative destruction and thereby encourages innovation. ${ }^{19}$ To the extent that innovation matters more for growth in more frontier economies, the prediction is:

Prediction 5: The correlation between democracy and innovation/growth is more positive and significant in more frontier economies.

The relationship between democracy, "frontierness" and growth, thus provides yet another illustration of our notion of appropriate institutions. In the next subsection we develop a simple Schumpeterian model which generates this prediction.

\subsubsection{The formal argument}

Consider the following Schumpeterian model in discrete time. All agents and also firms live for one period. In each period $t$ a final good (henceforth the numeraire) is produced in each state by a competitive sector using a continuum one of intermediate inputs, according to the technology:

$$
\ln Y_{t}=\int_{0}^{1} \ln y_{j t} d j
$$

where the intermediate products are produced again by labor according to

$$
y_{j t}=A_{j t} l_{j t}
$$

There is a competitive fringe of firms in each sector that are capable of producing a product with technology level $A_{j t} / \gamma$. So, as before, each incumbent's profit flow is

$$
\pi_{j t}=\pi Y_{t}
$$

where $\pi \equiv \frac{\gamma-1}{\gamma}$. Note that as in (19), each incumbent will produce using the same amount of labor

$$
l_{j t}=\frac{Y_{t}}{\gamma w_{t}} \equiv l,
$$

where $l$ is the economy's total use of manufacturing labor. We assume that there is measure 1 unit of labor which is used only for production. Therefore $l=1$ implies

$$
w_{t}=\frac{Y_{t}}{\gamma}
$$

Finally, (24), (25) and (26) delivers the final output as a function of the aggregate productivity $A_{t}$ in this economy:

$$
Y_{t}=A_{t}
$$

where $\ln A_{t} \equiv \int_{0}^{1} \ln A_{j t} d j$ is the end-of-period- $t$ aggregate productivity index.

\footnotetext{
${ }^{19}$ Acemoglu and Robinson (2006) formalize another reason, also Schumpeterian, as to why democracy matters for innovation: namely, new innovations do not only destroy the economic rents of incumbent producers, they also threaten the power of incumbent political leaders.
} 
Technology and entry Let $\bar{A}_{t}$ denote the new world productivity frontier at date $t$ and assume that

$$
\bar{A}_{t}=\gamma \bar{A}_{t-1}
$$

with $\gamma>1$ is exogenously given. We shall again emphasize the distinction already made in the previous section, between sectors in which the incumbent producer is "neck-and-neck" with the frontier and those in which the incumbent firm is below the frontier: at the beginning of date $t$ a sector $j$ can either be at the current frontier, with productivity level $A_{j t}^{b}=\bar{A}_{t-1}$ (advanced sector) or one step below the frontier, with productivity level $A_{j t}^{b}=\bar{A}_{t-2}$ (backward sector). Thus imitation -or knowledge spillovers- in this model, mean that whenever the frontier moves up one step from $\bar{A}_{t-1}$ to $\bar{A}_{t}$, then automatically backward sectors also move up one step from $\bar{A}_{t-2}$ to $\bar{A}_{t-1}$.

In each intermediate sector $j$ only one incumbent firm $I_{j}$ and one potential entrant $E_{j}$ are active in each period. In this model, innovation in a sector is made only by a potential entrant $E_{j}$ since innovation does not change incumbent's profit rate. Before production takes place, potential entrant $E_{j}$ invests in R\&D in order to replace the incumbent $I_{j}$. If successful, it increases the current productivity of sector $j$ to $A_{j t}=\gamma A_{j t}^{b}$ and becomes the new monopolist and produces. Otherwise, the current incumbent preserves its monopoly right and produces with the beginning-of-period productivity $A_{j t}=A_{j t}^{b}$ and the period ends. The timing of events is described in Figure 8.

Figure 8: Timing of Events

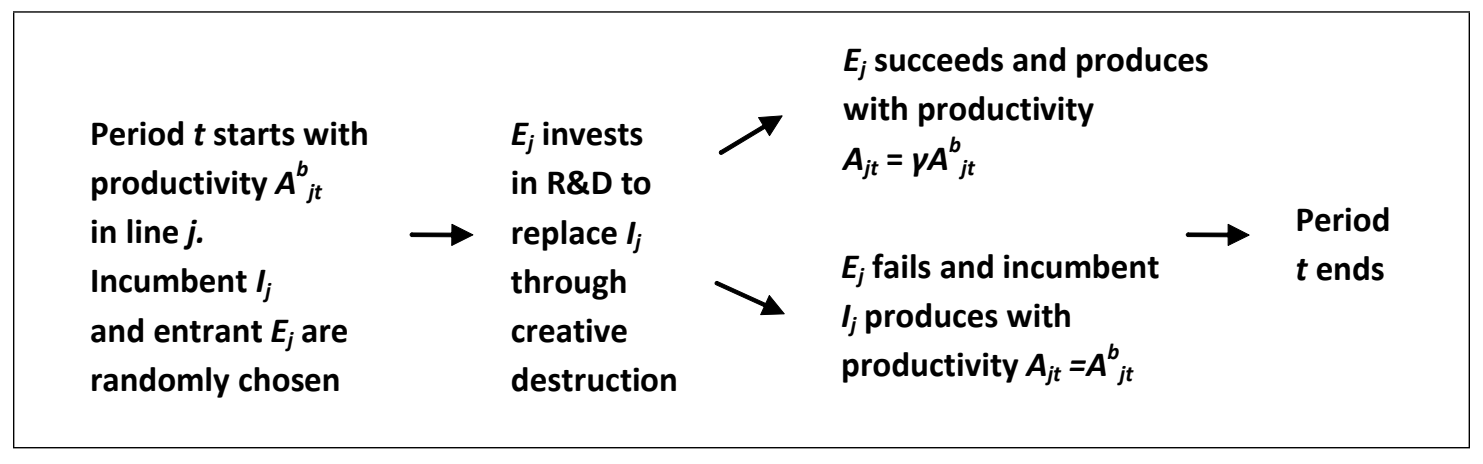

Finally, the innovation technology is as follows: if a potential entrant $E_{j}$ spends $A_{t} \lambda z_{j t}^{2} / 2$ in $\mathrm{R} \& \mathrm{D}$ in terms of the final good, then she innovates with probability $z_{j t}$.

Democracy Entry into a sector is subject to the democratic environment in the domestic country. Similar to Acemoglu and Robinson (2006), we model democracy as freedom to entry. More specifically, in a country with democracy level $\beta \in[0,1]$, a successful innovation leads to successful entry only with probability $\beta$, and it is blocked with probability $(1-\beta)$. As a result, the probability of an unblocked entry is $\beta z_{j}$. An unblocked entrant raises productivity from $A_{j t}^{b}$ to $\gamma A_{j t}^{b}$ and becomes the new monopoly producer.

Equilibrium innovation investments We can now analyze the innovation decision of the potential entrant $E_{j}$ :

$$
\max _{z_{j t}}\left\{z_{j t} \beta \pi Y_{t}-A_{t} \lambda \frac{z_{j t}^{2}}{2}\right\} .
$$


In equilibrium we get

$$
z_{j t}=\bar{z}=\frac{\beta \pi}{\lambda}
$$

where we used the fact that $Y_{t}=A_{t}$. Thus the aggregate equilibrium innovation effort is increasing in profit $\pi$ and decreasing in $\mathrm{R} \& \mathrm{D} \operatorname{cost} \lambda$. Most importantly for us in this section, innovation rate is increasing in the democracy level $\beta$ :

$$
\frac{\partial \bar{z}}{\partial \beta}>0
$$

Growth Now we can turn to the equilibrium growth rate of average productivity. We will denote the fraction of advanced sectors by $\mu$ which will also be the index for frontierness of the domestic country. The average productivity of a country at the beginning of date $t$ is

$$
A_{t-1} \equiv \int_{0}^{1} A_{j t} d j=\mu \bar{A}_{t-1}+(1-\mu) \bar{A}_{t-2}
$$

Average productivity at the end of the same period, is: ${ }^{20}$

$$
A_{t}=\mu\left[\beta \bar{z} \gamma \bar{A}_{t-1}+(1-\beta \bar{z}) \bar{A}_{t-1}\right]+(1-\mu) \bar{A}_{t-1}
$$

Then the growth rate of average productivity is simply equal to:

$$
g_{t}=\frac{A_{t}-A_{t-1}}{A_{t-1}}=\gamma \frac{\mu \beta \bar{z}(\gamma-1)+1}{\mu(\gamma-1)+1}-1>0
$$

As it is clear from the above expression, democracy is always growth enhancing

$$
\frac{\partial g_{t}}{\partial \beta}=\left(\bar{z}+\frac{\partial \bar{z}}{\partial \beta} \beta\right) \frac{\gamma \mu(\gamma-1)}{\mu(\gamma-1)+1}>0 .
$$

Moreover, democracy is more growth enhancing the closer the domestic country is to the world technology frontier:

$$
\frac{\partial^{2} g_{t}}{\partial \beta \partial \mu}=\left(\bar{z}+\frac{\partial \bar{z}}{\partial \beta} \beta\right) \frac{(\gamma-1) \gamma}{[\mu(\gamma-1)+1]^{2}}>0
$$

This result is quite intuitive. Democratization allows for more turnover which in turn encourages outsiders to innovate and replace the incumbents. Since frontier countries rely more on innovation and benefit less from imitation or spillover, the result follows.

\subsubsection{Evidence}

A first piece of evidence supporting Prediction 5, is provided by Aghion, Alesina and Trebbi (2007), henceforth AAT. The paper uses employment and productivity data at industry level across countries and over time. Their sample includes 28 manufacturing sectors for 180 countries over the period 1964 to 2003. Democracy is measured using the Polity 4 indicator, which

\footnotetext{
${ }^{20}$ Here we make use of the assumption that backward sectors are automatically upgraded as the technology frontier moves up.
} 
itself is constructed from combining constraints on the executive, the openness and competitiveness of executive recruitment, and the competitiveness of political participation. Frontierness is measured by the log of the value added of a sector divided by the maximum of the $\log$ of the same variable in the same sectors across all countries; or by ratio of the log of GDP per worker in the sector over the maximum of the log of per capita GDP in similar sectors across all countries. AAT take one minus these ratios as proxies for a sector's distance to the technological frontier. AAT focus on 5-year and 10-years growth rates. They compute rates over non-overlapping periods and in particular 5-years growth rates are computed over the periods $1975,1980,1985,1990,1995$, and 2000. For the 10-year growth rates they use alternatively the years 1975, 1985, 1995 and the years 1980, 1990, and 2000.

AAT regress growth of either value added or employment in an industrial sector on democracy (and other measures of civil rights), the country's or industry's frontierness, and the interaction term between the latter two. AAT also add time, country and industry fixed effects.

The result is that the interaction coefficient between frontierness and democracy is positive and significant, meaning that the more frontier the industry is, the more growth-enhancing democracy in the country is for that sector. Figure 9 below provides an illustration of the results. It plots the rate of value-added growth against a measure of the country's proximity to the technological frontier (namely the ratio of the country's labor productivity to the frontier labor productivity). The dotted line shows the linear regression of industry growth on democracy for countries that are less democratic than the median country (on the democracy scale), whereas the full line the corresponding relationship for countries that are more democratic than the median country. We see that growth is higher in more democratic countries when these are close to the technological frontier, but not when these are far below the frontier.

Figure 9: Growth, Democracy and Distance to Frontier

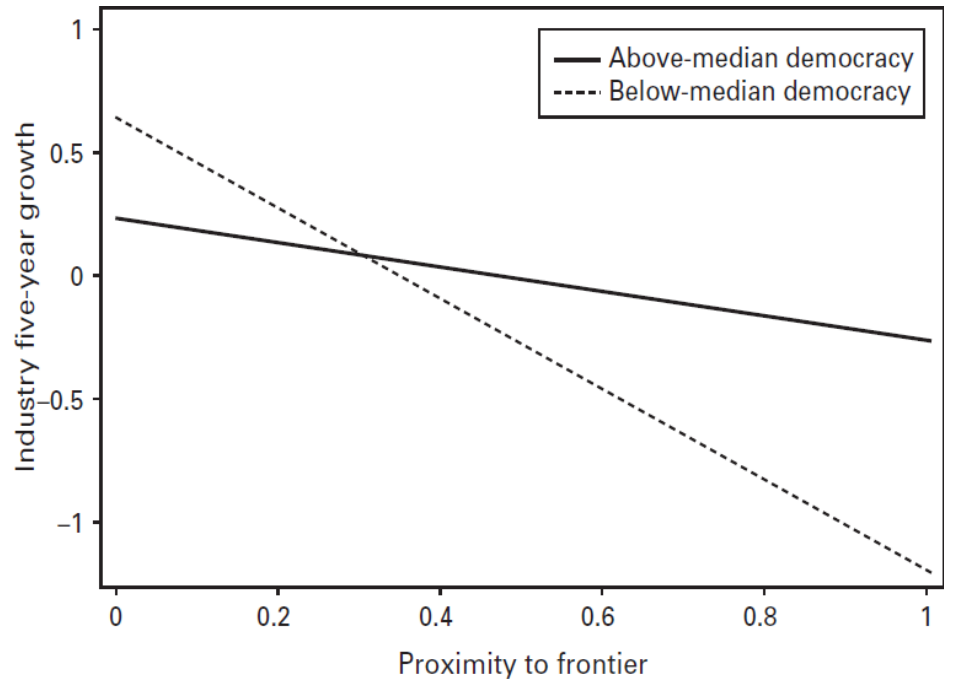




\section{Schumpeterian waves}

What causes long-term accelerations and slowdowns in economic growth, and underlies the long swings sometimes referred to as Kondratieff cycles? In particular, what caused American growth in GDP and productivity to accelerate starting in the mid-1990s? The most popular explanation relies on the notion of general-purpose technologies (GPTs).

Bresnahan and Trajtenberg (1995) define a GPT as a technological innovation that affects production and/or innovation in many sectors of an economy. Well-known examples in economic history include the steam engine, electricity, the laser, turbo reactors, and more recently the information-technology (IT) revolution. Three fundamental features characterize most GPTs. First, their pervasiveness: GPTs are used in most sectors of an economy and thereby generate palpable macroeconomic effects. Second, their scope for improvement: GPTs tend to underperform upon being introduced; only later do they fully deliver their potential productivity growth. Third, innovation spanning: GPTs make it easier to invent new products and processes - that is, to generate new secondary innovations- of higher quality.

Although each GPT raises output and productivity in the long run, it can also cause cyclical fluctuations while the economy adjusts to it. As David (1990) and Lipsey and Bekar (1995) have argued, GPTs like the steam engine, the electric dynamo, the laser, and the computer require costly restructuring and adjustment to take place, and there is no reason to expect this process to proceed smoothly over time. Thus, contrary to the predictions of real-businesscycle theory, the initial effect of a "positive technology shock" may not be to raise output, productivity, and employment but to reduce them. ${ }^{21}$

Note that GPTs are Schumpeterian in nature, as they typically lead to older technologies in all sectors of the economy to be abandoned as they diffuse to these sectors. Thus it is no surprise that Helpman and Trajtenberg (1998) used the Schumpeterian apparatus to develop their model of GPT and growth. The basic idea of this model is that GPTs do not come ready to use off the shelf. Instead, each GPT requires an entirely new set of intermediate goods before it can be implemented. The discovery and development of these intermediate goods is a costly activity, and the economy must wait until some critical mass of intermediate components has been accumulated before it is profitable for firms to switch from the previous GPT. During the period between the discovery of a new GPT and its ultimate implementation, national income will fall as resources are taken out of production and put into $R \& D$ activities aimed at the discovery of new intermediate input components.

\subsection{Back to the basic Schumpeterian model}

As a useful first step toward a growth model with GPT, let us go back to the basic Schumpeterian model outlaid in Section 2, but present it somewhat differently. Recall that the representative household has linear utility and the final good is produced with a single intermediate product according to

$$
Y_{t}=A_{t} y^{\alpha}
$$

where $y$ is the flow of intermediate input and $A$ is the productivity parameter measuring the quality of intermediate input $y$.

\footnotetext{
${ }^{21}$ For instance, Greenwood and Yorukoglu (1997) and Hornstein and Krusell (1996) have studied the productivity slowdown during late 70 s and early 80 s caused by the IT revolution.
} 
Each innovation results in an intermediate good of higher quality. Specifically, a new innovation multiplies the productivity parameter $A_{k}$ by $\gamma>1$, so that

$$
A_{k+1}=\gamma A_{k}
$$

Innovations in turn arrive discretely with Poisson rate $\lambda z$, where $z$ is the current flow of research.

In steady state the allocation of labor between research and manufacturing remains constant over time, and is determined by the research arbitrage equation

$$
\omega_{k}=\lambda \gamma v_{k}
$$

where the LHS of (27) is the productivity-adjusted wage $\omega_{k} \equiv w_{k} / A_{k}$, which a worker earns by working in the manufacturing sector; $v_{k} \equiv V_{k} / A_{k}$ is the productivity-adjusted value and $\lambda \gamma v_{k}$ is the expected reward from investing one unit flow of labor in research. ${ }^{22}$ The productivityadjusted value $v_{k}$ of an innovation is in turn determined by the Bellman equation

$$
\rho v_{k}=\tilde{\pi}\left(\omega_{k}\right)-\lambda z v_{k}
$$

where $\pi\left(\omega_{k}\right)=A_{k}[1-\alpha] \alpha^{\frac{1+\alpha}{1-\alpha}} \omega_{k}^{\frac{\alpha}{\alpha-1}}$ is the equilibrium profit and $\tilde{\pi}\left(\omega_{k}\right) \equiv \pi\left(\omega_{k}\right) / A_{k}$ denotes the productivity-adjusted flow of monopoly profits accruing to a successful innovator and we used the fact that $r_{t}=\rho$. In $(28)$ the term $(-\lambda z v)$ corresponds to the capital loss involved in being replaced by a subsequent innovator. In steady state, the productivity-adjusted variables $\omega_{k}$ and $v_{k}$ remain constant, therefore the subscript $k$ will henceforth be dropped.

The above arbitrage equation, which can now be reexpressed as

$$
\omega=\lambda \gamma \frac{\tilde{\pi}(\omega)}{\rho+\lambda z}
$$

together with the labor-market clearing condition

$$
y(\omega)+z=L
$$

where $y(\omega)$ is the manufacturing demand for labor, jointly determine the steady-state amount of research $z$ as a function of the parameters $\lambda, \gamma, L, \rho, \alpha$.

In a steady-state the flow of final good produced between the $k^{\text {th }}$ and $(k+1)^{t h}$ innovation is

$$
Y_{k}=A_{k}[L-z]^{\alpha} .
$$

Thus the $\log$ of final output increases by $\ln \gamma$ each time a new innovation occurs. Then the average growth rate of the economy is equal to the size of each step $\ln \gamma$ times the average number of innovations per unit of time, $\lambda z$ : i.e.

$$
\mathbb{E}(g)=\lambda z \ln \gamma
$$

\footnotetext{
${ }^{22}$ Equation (27) is just a rewrite of equation $(\mathrm{R})$ in Section 2: recall that the latter is expressed as $w_{k}=\lambda V_{k+1}$
}

using the fact that $V_{k+1}=\gamma V_{k}$, this immediately leads to equation (27). 
Note that this is a one-sector economy where each innovation corresponds by definition to a major technological change (i.e., to the arrival of a new GPT), and thus where growth is uneven with the time path of output being a random step function. But although it is uneven, the time path of aggregate output does not involve any slump. Accounting for the existence of slumps requires an extension of the basic Schumpeterian model, which brings us to the GPT growth model.

\subsection{A model of growth with GPTs}

As before, there are $L$ workers who can engage either in production of existing intermediate goods or in research aimed at discovering new intermediate goods. Again, each intermediate good is linked to a particular GPT. We follow Helpman and Trajtenberg (1998) in supposing that before any of the intermediate goods associated with a GPT can be used profitably in the final-goods sector, some minimal number of them must be available. We lose nothing essential by supposing that this minimal number is one. Once the good has been invented, its discoverer profits from a patent on its exclusive use in production, exactly as in the basic Schumpeterian model reviewed earlier.

Thus the difference between this model and our basic model is that now the discovery of a new generation of intermediate goods comes in two stages. First a new GPT must come, and then the intermediate good must be invented that implements that GPT. Neither can come before the other. You need to see the GPT before knowing what sort of good will implement it, and people need to see the previous GPT in action before anyone can think of a new one. For simplicity we assume that no one directs R\&D toward the discovery of a new GPT. Instead, the discovery arrives as a serendipitous by-product of learning by doing with the previous one.

Figure 10: Phases of GPT Cycles

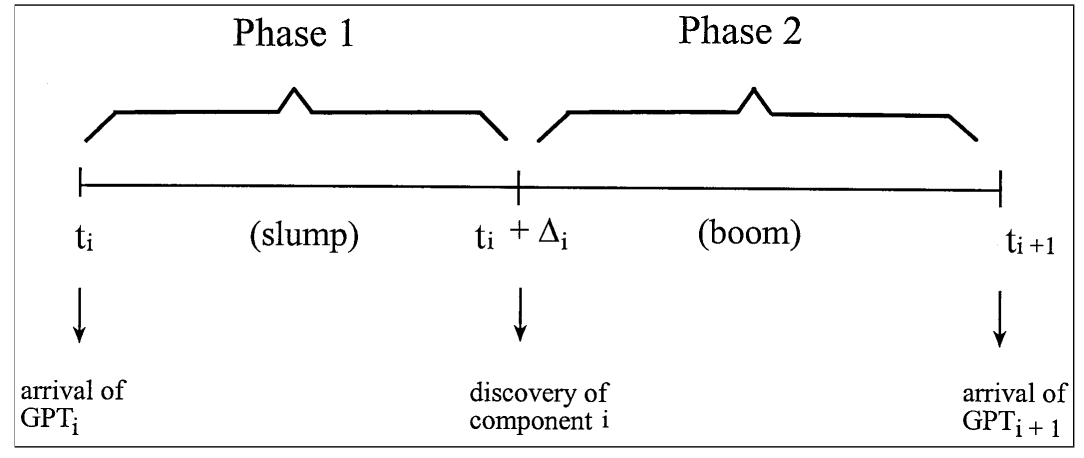

The economy will pass through a sequence of cycles, each having two phases, as indicated in Figure 10. $G P T_{i}$ arrives at time $T_{i}$. At that time the economy enters phase 1 of the $i^{\text {th }}$ cycle. During phase 1, the amount $z$ of labor is devoted to research. Phase 2 begins at time $T_{i}+\Delta_{i}$ when this research discovers an intermediate good to implement $G P T_{i}$. During phase 2 all labor is allocated to manufacturing until $G P T_{i+1}$ arrives, at which time the next cycle begins. Over the cycle, output is equal to $A_{i-1} F(L-z)$ during phase 1 and to $A_{i} F(L)$ during phase 2. Thus the drawing of labor out of manufacturing and into research causes output to fall each time a GPT is discovered, by an amount equal to $A_{i-1}[F(L)-F(L-z)]$.

A steady-state equilibrium is one in which people choose to do the same amount of research each time the economy is in phase 1; that is, $z$ is constant from one GPT to the next. As before, 
we can solve for the equilibrium value of $z$ using a research-arbitrage equation and a labormarket-equilibrium condition. Let $\omega_{j}$ be the (productivity-adjusted) wage, and $v_{j}$ the expected (productivity-adjusted) present value of the incumbent (intermediate good) monopolist when the economy is in phase $j \in\{1,2\}$. In a steady state these productivity-adjusted variables will all be independent of which GPT is currently in use.

Because research is conducted in phase 1 but pays off when the economy enters into phase 2 with a productivity parameter raised by the factor $\gamma$, the following research-arbitrage condition must hold in order for there to be a positive level of research in the economy

$$
\omega_{1}=\lambda \gamma v_{2}
$$

Suppose that once we are in phase 2, the new GPT is delivered by a Poisson process with constant arrival rate $\mu$. Then the value $v_{2}$ is determined by the Bellman equation

$$
\rho v_{2}=\tilde{\pi}\left(\omega_{2}\right)+\mu\left[v_{1}-v_{2}\right] .
$$

By analogous reasoning, we have:

$$
\rho v_{1}=\widetilde{\pi}\left(\omega_{1}\right)-\lambda z v_{1}
$$

Combining the above three equations, yields the research arbitrage equation:

$$
\omega_{1}=\frac{\lambda \gamma}{\rho+\mu}\left[\tilde{\pi}\left(\omega_{2}\right)+\frac{\mu \widetilde{\pi}\left(\omega_{1}\right)}{\rho+\lambda z}\right]
$$

Because no one does research in phase 2 , we know that the value of $\omega_{2}$ is determined independently of research, by the market-clearing condition

$$
L=y\left(\omega_{2}\right) .
$$

Thus we can take this value as given and regard the preceding research-arbitrage condition (29) as determining $\omega_{1}$ as a function of $z$. The value of $z$ is then determined, as in the previous subsection, by the labor-market equation

$$
L-z=y\left(\omega_{1}\right)
$$

The average growth rate will be the frequency of innovations times the size $\ln \gamma$, for exactly the same reason as in the basic model. The frequency, however, is determined a little differently than before because the economy must pass through two phases. An innovation is implemented each time a full cycle is completed. The frequency with which this implementation occurs is the inverse of the expected length of a complete cycle. This in turn is just the expected length of phase 1 plus the expected length of phase $2: 1 / \lambda z+1 / \mu=[\mu+\lambda z] / \mu \lambda z$. Thus the growth rate will be

$$
g=\ln \gamma \frac{\mu \lambda z}{\mu+\lambda z}
$$

which is positively affected by anything that raises research. Note also that growth tapers off in the absence of the arrival of new GPTs, i.e. if $\mu=0$. This leads Gordon (2012) to predict a 
durable slowdown of growth in the US and other developed economies as the ITC revolution is running out of steam.

The size of the slump $\ln (F(L))-\ln (F(L-z))$ that occurs when each GPT arrives is also an increasing function of $z$, and hence it will tend to be positively correlated with the average growth rate.

One further property of this cycle worth mentioning is that the wage rate will rise when the economy goes into a slump. That is, because there is no research in phase 2 , the normalized wage must be low enough to provide employment for all $L$ workers in the manufacturing sector, whereas with the arrival of the new GPT the wage must rise to induce manufacturers to release workers into research. This brings us directly to the next subsection on wage inequality.

\subsection{GPT and wage inequality}

In this subsection we show how the model of the previous section can account for the rise in the skill premium during the IT revolution. We modify that model by assuming that there are two types of labor. Educated labor can work in both research and manufacturing, whereas uneducated labor can only work in manufacturing. Let $L^{s}$ and $L^{u}$ denote the supply of educated (skilled) and uneducated (unskilled) labor, let $\omega_{1}^{s}$ and $\omega_{1}^{u}$ denote their respective productivityadjusted wages in phase 1 of the cycle (when research activities on complementary inputs actually take place), and let $\omega_{2}$ denote the productivity-adjusted wage of labor in phase 2 (when new GPTs have not yet appeared and therefore labor is entirely allocated to manufacturing).

If in equilibrium the labor market is segmented in phase 1, with all skilled labor being employed in research while unskilled workers are employed in manufacturing, we have the labor-market-clearing conditions

$$
L^{s}=z, \quad L^{u}=y\left(\omega_{1}^{u}\right), \text { and } L^{s}+L^{u}=y\left(\omega_{2}\right)
$$

and the research-arbitrage condition

$$
\omega_{1}^{s}=\lambda \gamma v_{2}
$$

where $v_{2}$ is the productivity-adjusted value of an intermediate producer in stage 2 . This value is itself determined as before by the two Bellman equations:

$$
\rho v_{2}=\tilde{\pi}\left(\omega_{2}\right)+\mu\left[v_{1}-v_{2}\right]
$$

and:

$$
\rho v_{1}=\widetilde{\pi}\left(\omega_{1}^{u}\right)-\lambda z v_{1} .
$$

Thus the above research-arbitrage equation (30) expresses the wage of skilled labor as being equal to the expected value of investing (skilled) labor in $R \& D$ for discovering complementary inputs to the new GPT.

The labor market will be truly segmented in phase 1 if and only if $\omega_{1}^{s}$ defined by researcharbitrage condition (30) satisfies:

$$
\omega_{1}^{s}>\omega_{1}^{u}
$$

which in turn requires that $L^{s}$ not be too large. Otherwise the labor market remains unsegmented, with $z<L^{s}$ and

$$
\omega_{1}^{s}=\omega_{1}^{u}
$$


in equilibrium. In the former case, the arrival of a new GPT raises the skill premium (from 0 to $\left.\omega_{1}^{s} / \omega_{1}^{u}-1\right)$ at the same time as it produces a productivity slowdown because labor is driven out of production.

\subsection{Predictions}

The above GPT model delivers the following predictions. ${ }^{23}$

Prediction 1: The diffusion of a new GPT is associated with an increase in the flow of firm entry and exit.

This results from the fact that the GPT is Schumpeterian in nature, thus generates qualityimproving innovations, and therefore creative destruction, in numerous sectors of the economy as it diffuses to those sectors. It also explains the observed surge of financial sectors during the acceleration phase in the diffusion of new GPTs, as shown by Philippon (2008).

Prediction 2: The arrival of a new GPT generates a slowdown in productivity growth; this slowdown is mirrored by a decline in stock market prices.

The diffusion of a new GPT requires complementary inputs and learning, which may draw resources from normal production activities and may contribute to future productivity in a way that cannot be captured easily by current statistical indicators. Another reason why the diffusion of a new GPT should reduce growth in the short run is by inducing obsolescence of existing capital in the sectors it diffuses to (see Aghion and Howitt $(1998,2009)$ ).

Prediction 3: The diffusion of a new GPT generates an increase in wage inequality both between and within educational groups.

An increase in the skill premium occurs as more skilled labor is required to diffuse a new GPT to all the sectors of the economy as we saw above. The other and perhaps most intriguing feature of the upsurge in wage inequality is that it took place to a large extent within control groups, no matter how narrowly those groups are identified (e.g., in terms of experience, education, gender, industry, occupation). One explanation is that skill-biased technical change enhanced not only the demand for observed skills as described earlier but also the demand for unobserved skills or abilities. Although theoretically appealing, this explanation is at odds with econometric work (Blundell and Preston (1999)) showing that the within-group component of wage inequality in the United States and United Kingdom is mainly transitory, whereas the between-group component accounts for most of the observed increase in the variance of permanent income. The explanation based on unobserved innate abilities also fails to explain why the rise in within-group inequality has been accompanied by a corresponding rise in individual wage instability (see Gottschalk and Moffitt (1994)). Using a GPT approach, Aghion, Howitt, and Violante (2002) argue that the diffusion of a new technological paradigm can affect the evolution of within-group wage inequality in a way that is consistent with these facts. The diffusion of a new GPT raises within-group wage inequality primarily because the rise in the speed of embodied technical progress associated with the diffusion of the new GPT increases the market premium to those workers who adapt quickly to the leading-edge technology and are therefore able to survive the process of creative destruction at work as the GPT diffuses

\footnotetext{
${ }^{23}$ While Jovanovic and Rousseau (2005) provide evidence for the first three prediction, we refer the reader to Acemoglu (2002; 2009), Aghion, Caroli and Garcia-Penalosa (1999), and Aghion and Howitt (2009) for evidence on growth and wage inequality. In particular Aghion and Howitt contrast the GPT explanation with alternative explanations based on trade, deunionization, or directed technical change considerations.
} 
to the various sectors of the economy. ${ }^{24}$

\section{Conclusion}

In this paper, we argued that Schumpeterian growth theory - where current innovators exert positive knowledge spillovers on subsequent innovators as in other innovation-based models, but where current innovators also drive out previous technologies-, generates predictions and explains facts about the growth process that could not be accounted for by other theories.

In particular, we saw how Schumpeterian growth theory manages to put IO into growth, and to link growth with firm dynamics, thereby generating predictions on the dynamic patterns of markets and firms (entry, exit, reallocation,..) and on how these patterns shape the overall growth process. These predictions and the underlying models can be confronted to micro data and this confrontation in turn helps refine the models. This back-and-forth communication between theory and data has been key to the development of the Schumpeterian growth theory over the past 25 years. ${ }^{25}$

Also, we argued that Schumpeterian growth theory helps us reconcile growth with development, in particular by bringing out the notion of appropriate growth institutions and policies, i.e. the idea that what drives growth in a sector (or country) far below the world technology frontier, is not necessarily what drives growth in a sector or country at the technological frontier where creative destruction plays a more important role. In particular we pointed to democracy being more-growth enhancing in more frontier economies. The combination of the creative destruction and appropriate growth institutions ideas also underlies the view ${ }^{26}$ that "extractive economies" where creative destruction is deterred by political elites, are more likely to fall in low-growth traps.

Beyond enhancing our understanding of the growth process, Schumpeterian growth theory is useful in at least two respects. First, as a tool for growth policy design: departing from the "Washington consensus" view whereby the same policies should be recommended everywhere, the theory points to appropriate growth policies, i.e. policies that match the particular context of a country or region. Thus we saw that more intense competition (lower entry barriers), a

\footnotetext{
${ }^{24}$ In terms of the preceding model, let us again assume that all workers have the same level of education but that once a new GPT has been discovered, only a fraction $\alpha$ of the total labor force can adapt quickly enough to the new technology so that they can work on looking for a new component that complements the GPT. The other workers that did not successfully adapt have no alternative but to work in manufacturing. Let $\omega_{1}^{\text {adapt }}$ denote the productivity-adjusted wage rate of adaptable workers in phase 1 of the cycle, whereas $\omega_{1}$ denotes the wage of nonadaptable workers. Labor market clearing implies: $\alpha L=z ;[1-\alpha] L=y\left(\omega_{1}\right) ; L=y\left(\omega_{2}\right)$ whereas research arbitrage for adaptable workers in phase 1 implies $\omega_{1}^{\text {adapt }}=\lambda \gamma v_{2}$. When $\alpha$ is sufficiently small the model generates a positive adaptability premium: $\omega_{1}^{\text {adapt }}>\omega_{1}$.

${ }^{25}$ For example, when analyzing the relationship between growth and firm dynamics, this back-and-forth process amounts to what one might call a layered approach. Here we refer the reader to Daron Acemoglu's panel discussion at the Nobel Symposium on Growth and Development (September 2012). The idea here is that of a "step-by-step" estimation method where at each step a small subset of parameters are being identified in their neighborhood. Thanks to the rich set of available micro data, one can first identify a parameter and its partial equilibrium effect as well as some of its industry equilibrium effects. Next, one can test the predictions of the model using moments in the data that were not directly targeted in the original estimation. Then one can check that the model also satisfies various out of sample properties and reach to a macro aggregation by building on detailed micro moments. Schumpeterian models are well suited for this type of approach as they are able to generate realistic firm dynamics with tractable aggregations.

${ }^{26}$ See Acemoglu and Robinson (2012).
} 
higher degree of trade openness, more emphasis on research education, all of these are more growth-enhancing in more frontier countries. ${ }^{27}$

The Schumpeterian growth paradigm also helps assess the relative magnitude of counteracting partial equilibrium effects pointed out by the theoretical IO literature. For example there is a whole literature on competition, investments and incentives ${ }^{28}$, which points at counteracting partial equilibrium effects without saying much as to when one particular effect should be expected to prevail. In contrast, Section 3 illustrated how aggregation and the resulting composition effect could help determine under which circumstances the escape competition effect would dominate the counteracting Schumpeterian effect. Similarly, Section 4 showed the importance of reallocation for growth: thus policies supporting entry or incumbent R\&D could contribute positively to economic growth in partial equilibrium, yet general equilibrium showed that this is done at the expense of reduced innovation by the rest of the economy.

Where do we see the Schumpeterian growth agenda being pushed over the next years? A first direction is to look more closely at how growth and innovation are affected by the organization of firms and research. Thus over the past five years Nick Bloom and John Van Reenen have popularized fascinating new data sets that allow us to look at how various types of organizations (e.g. more or less decentralized firms) are more or less conducive to innovation. But firms' size and organization are in turn endogenous, and in particular they depend upon factors such as the relative supply of skilled labor or the nature of domestic institutions.

A second and related avenue for future research is to look at growth, firm dynamics and reallocation in developing economies. Recent empirical evidence (see Hsieh and Klenow 2009, 2012) has shown that misallocation of resources is a major source of productivity gap across countries. What are the causes of misallocation, why do these countries lack creative destruction which would eliminate the inefficient firms? Schumpeterian theory with firm dynamics could be an invaluable source to shed light on these important issues that lie at the core of the development puzzle.

A third avenue is to look at the role of finance in the growth process. In Section 5 we pointed at equity finance being more growth-enhancing in more frontier economies. More generally, we still need to better understand how different types of financial instruments map with different sources of growth and different types of innovation activities. Also, we need to better understand why we observe a surge of finance during the acceleration phase in the diffusion of new technological waves, as mentioned in Section 6, and also how financial sectors evolve when the waves taper off. These and many other microeconomic aspects of innovation and growth await further research.

\footnotetext{
${ }^{27}$ Parallel studies point at labor market liberalization and stock market finance being more growth-enhancing in more advanced countries or regions.

${ }^{28}$ See the recent analytical surveys by Gilbert (2006), Vives (2008), and Schmutzler (2010).
} 


\section{References}

[1] Acemoglu, D. (2002). "Technical Change, Inequality, and the Labor Market." Journal of Economic Literature, 40, 7-72.

[2] Acemoglu, D. (2009). Introduction to Modern Economic Growth, Princeton University Press.

[3] Acemoglu, D., P. Aghion, and F. Zilibotti. (2006). "Distance to Frontier, Selection, and Economic Growth." Journal of the European Economic Association, 37-74.

[4] Acemoglu, D. and U. Akcigit. (2012). "Intellectual Property Rights Policy, Competition and Innovation." Journal of the European Economic Association, 10, 1-42.

[5] Acemoglu, D., U. Akcigit, N. Bloom, and W. Kerr. (2012). "Innovation, Reallocation and Growth." University of Pennsylvania mimeo.

[6] Acemoglu, D., U. Akcigit, D. Hanley, and W. Kerr. (2012). "Transition to Clean Technology." University of Pennsylvania mimeo.

[7] Acemoglu, D. and D. Cao. (2011). "Innovation by Entrants and Incumbents." MIT mimeo.

[8] Acemoglu, D. and J. Robinson. (2006). "Economic Backwardness in Political Perspective." American Political Science Review, 100, 115-131.

[9] Acemoglu, D. and J. Robinson. (2012). Why Nations Fail, Crown Business.

[10] Acs, Z. and D. Audretsch. (1988). "Innovation in Large and Small Firms: An Empirical Analysis." American Economic Review 78, 678-690.

[11] Acs, Z. and D. Audretsch. (1991). "Innovation and Size at the Firm Level." Southern Economic Journal 57, 739-744.

[12] Aghion, P., A. Alesina, and F. Trebbi. (2007). "Democracy, Technology and Growth." in E. Helpman (ed.), Institutions and Economic Performance, Cambridge University Press.

[13] Aghion, P., N. Bloom, R. Blundell, R. Griffith, and P. Howitt. (2005). "Competition and Innovation: An Inverted-U Relationship." Quarterly Journal of Economics, 120, 701-728.

[14] Aghion, P., R. Blundell, R. Griffith, P. Howitt, and S. Prantl. (2009). "The Effects of Entry on Incumbent Innovation and Productivity." Review of Economics and Statistics, 91, 20-32.

[15] Aghion, P., L. Boustan, C. Hoxby, and J. Vandenbussche. (2009). " Exploiting States' Mistakes to Identify the Causal Effects of Higher Education on Growth." Harvard mimeo.

[16] Aghion, P., E. Caroli, and C. Garcia-Penalosa. (1999). "Inequality and Economic Growth: The Perspective of the New Growth Theories." Journal of Economic Literature, 37, 16151660 .

[17] Aghion, P., M. Dewatripont, and J. Stein. (2008). "Academic Freedom, Private Sector Focus, and The Process of Innovation." RAND Journal of Economics, 39, 617-635. 
[18] Aghion, P. and R. Griffith. (2006). Competition and Growth: Reconciling Theory and Evidence, MIT Press.

[19] Aghion, P., C. Harris, P. Howitt, and J. Vickers. (2001). "Competition, Imitation and Growth with Step-by-Step Innovation." Review of Economic Studies, 68, 467-492.

[20] Aghion, P., C. Harris, and J. Vickers. (1997). "Competition and Growth with Step-by-Step Innovation: An Example." European Economic Review, Papers and Proceedings, 771-782.

[21] Aghion, P. and P. Howitt. (1992). "A Model of Growth Through Creative Destruction", Econometrica, 60, 323-351.

[22] Aghion, P. and P. Howitt. (1998). Endogenous Growth Theory, MIT Press.

[23] Aghion, P. and P. Howitt. (2009). The Economics of Growth, MIT Press.

[24] Aghion, P., P. Howitt, and S. Prantl. (2012). "Patent Protection, Product Market Reforms and Innovative Investments." Harvard mimeo.

[25] Aghion, P., P. Howitt, and G. Violante. (2002). "General Purpose Technology and Wage Inequality." Journal of Economic Growth, 7, 315-345.

[26] Akcigit, U., D. Hanley, and N. Serrano-Velarde. (2012). "Back to Basics: Basic Research Spillovers, Innovation Policy and Growth." University of Pennsylvania mimeo.

[27] Akcigit, U. and W. Kerr. (2010). "Growth through Heterogeneous Innovations", NBER Working Paper 16443.

[28] Alesina, A. and D. Rodrik. (1994). "Distributive Politics and Economic Growth.” Quarterly Journal of Economics, 109, 465-490.

[29] Arrow, K. (1962). "The Economic Implications of Learning by Doing." Review of Economic Studies, 29, 155-173.

[30] Axtell, R. (2001). "Zipf Distribution of US Firm Sizes.” Science, 293, 1818-1820.

[31] Barro, R. J. and X. Sala-i-Martin. (2003). Economic Growth, McGraw-Hill.

[32] Bartelsman, E. and M. Doms. (2000). "Understanding Productivity: Lessons from Longitudinal Microdata." Journal of Economic Literature, 38, 569-594.

[33] Bartelsman, E., J. Haltiwanger, and S. Scarpetta. (2009). "Cross-country Differences in Productivity: The Role of Allocation and Selection" NBER Working Paper 15490.

[34] Birch, D. (1981). "Who Creates Jobs?" The Public Interest, 65, 3-14.

[35] Birch, D. (1987). Job Creation in America: How Our Smallest Companies Put the Most People to Work, Free Press.

[36] Blundell, R., R. Griffith, and J. Van Reenen. (1995). "Dynamic Count Data Models of Technological Innovation." Economic Journal, 105, 333-344. 
[37] Blundell, R., R. Griffith, and J. Van Reenen. (1999). "Market Share, Market Value and Innovation in a Panel of British Manufacturing Firms." Review of Economic Studies, 66, 529-554.

[38] Blundell, R. and I. Preston. (1999). "Inequality and uncertainty: Short-Run Uncertainty and Permanent Inequalityin the US and Britain", University College London mimeo.

[39] Boldrin, M. and D. Levine. (2008). Against Intellectual Monopoly, Cambridge University Press.

[40] Bresnahan, T. and M. Trajtenberg. (1995). "General Purpose Technologies: Engines of Growth?." Journal of Econometrics, 65, 83-108.

[41] Cohen, W. (1995). "Empirical Studies of Innovative Activity." in Paul Stoneman (ed.) Handbook of the Economics of Innovations and Technological Change, Blackwell.

[42] Cohen, W., and S. Klepper. (1996). "Firm Size and the Nature of Innovation within Industries: The Case of Process and Product R\&D." Review of Economics and Statistics, $232-243$.

[43] Corriveau, L. (1991). "Entrepreneurs, Growth, and Cycles", PhD dissertation, University of Western Ontario.

[44] David, P. (1990). "The Dynamo and the Computer: An Historical Perspective on the Modern Productivity Paradox." American Economic Review, 80, 355-361.

[45] Davis, S., J. Haltiwanger, and S. Schuh. (1996). Job Creation and Destruction, MIT Press.

[46] Djankov, S., R. La Porta, F. Lopez-de-Silanes, and A. Shleifer. (2002). "The Regulation of Entry." Quarterly Journal of Economics, 117, 1-37.

[47] Foster, L., J. Haltiwanger, and C. Krizan. (2001). "Aggregate Productivity Growth: Lessons from Microeconomic Evidence," New Directions in Productivity Analysis (eds. E. Dean, M. Harper and C. Hulten), University of Chicago Press.

[48] Foster, L., J. Haltiwanger, and C. Krizan. (2006). "Market Selection, Reallocation, and Restructuring in the U.S. Retail Trade Sector in the 1990s, " The Review of Economics and Statistics, 88, 748-758.

[49] Frankel, J. and D. Romer. (1999). "Does Trade Cause Growth?." American Economic Review, 89, 379-399.

[50] Freeman, C. (1982). The Economics of Industrial Innovation. MIT Press.

[51] Galor, O. (2011). Unified Growth Theory, Princeton University Press.

[52] Gerschenkron, A. (1962). Economic Backwardness in Historical Perspective: A Book of Essays. Belknap Press of Harvard University Press.

[53] Gilbert, R. (2006). "Looking for Mr Schumpeter: Where Are We in the CompetitionInnovation Debate?." In J. Lerner and S. Stern (Eds) Innovation Policy and Economy, NBER, MIT Press. 
[54] Gordon, R. (2012). "Is U.S. Economic Growth Over? Faltering Innovation Confronts the Six Headwinds." NBER Working Paper 18315.

[55] Gottschalk, P. and R. Moffitt. (1994). "The Growth of Earnings Instability in the US Labor Market." Brookings Papers on Economic Activity, 2, 217-272.

[56] Greenwood, J. and M. Yorukoglu. (1997). "1974." Carnegie-Rochester Series on Public Policy, 46, 49-95.

[57] Griliches, Z. (1990). "Patent Statistics as Economic Indicators: A Survey." Journal of Economic Literature 28, 1661-1707.

[58] Grossman, G. and E. Helpman. (1991). "Quality Ladders in the Theory of Growth." Review of Economic Studies, 58, 43-61.

[59] Hall, B., A. Jaffe, and M. Trajtenberg. (2001). "The NBER Patent Citation Data File: Lessons, Insights and Methodological Tools." NBER Working Paper 8498.

[60] Haltiwanger, J., R. Jarmin, and J. Miranda. (2010). "Who Creates Jobs? Small vs. Large vs. Young." NBER Working Paper 16300.

[61] Helpman, E. and M. Trajtenberg. (1998). "A Time to Sow and A Time to Reap: Growth Based on General Purpose Technologies." in Helpman, E (Ed.) General Purpose Technologies and Economic Growth, MIT Press.

[62] Hornstein, A. and P. Krusell. (1996). "Can Technology Improvements Cause Productivity Slowdowns?" NBER Macroeconomics Annual, 11, 209-259.

[63] Howitt, P. (2000). "Endogenous Growth and Cross-Country Income Differences." American Economic Review, 90, 829-46.

[64] Hsieh, C. and P. Klenow. (2009). "Misallocation and Manufacturing TFP in China and India." Quarterly Journal of Economics, 124, 1403-1448.

[65] Hsieh, C. and P. Klenow. (2012). "The Life Cycle of Plants in India and Mexico." NBER Working Paper 18133.

[66] Ijiri, Y. and H. Simon. (1977). Skew Distributions and the Sizes of Business Firms. NorthHolland.

[67] Jones, C. and D. Vollrath. (2013). Introduction to Economic Growth, W. W. Norton \& Company.

[68] Jovanovic, B. and P. Rousseau. (2005). "General Purpose Technologies", In P. Aghion and S. Durlauf (Eds.), Handbook of Economic Growth, Elsevier, North-Holland.

[69] Klette, T. and S. Kortum. (2004). "Innovating Firms and Aggregate Innovation", Journal of Political Economy 112, 986-1018.

[70] Lentz, R. and D. Mortensen. (2008). "An Empirical Model of Growth through Product Innovation", Econometrica 76, 1317-1373. 
[71] Lipsey, R. and C. Bekar. (1995). "A Structuralist View of Technical Change and Economic Growth." Bell Canada Papers on Economic and Public Policy, 3, 9-75.

[72] Nelson, R. and E. Phelps. (1966). "Investment in Humans, Technological Diffusion, and Economic Growth." American Economic Review, 61, 69-75.

[73] Neumark, D., B. Wall, and J. Zhang. (2008). "Do Small Businesses Create More Jobs? New Evidence for the United States from the National Establishment Time Series." NBER Working Paper 13818.

[74] Nickell, S. (1996). "Competition and Corporate Performance." Journal of Political Economy, 104, 724-746.

[75] Pennings, J. M. and A. Buitendam. (1987). New Technology As Organizational Innovation: The Development and Diffusion of Microelectronics. Bollinger.

[76] Peretto, P. (1998). "Technological Change, Market Rivalry, and the Evolution of the Capitalist Engine of Growth", Journal of Economic Growth, 3, 53-80.

[77] Persson, T. and G. Tabellini. (1994). "Is Inequality Harmful for Growth?." American Economic Review, 84, 600-621.

[78] Philippon, T. (2008). " The Evolution of the US Financial Industry from 1880 to 2007: Theory and Evidence." NYU mimeo.

[79] Qian, Y. (2007). "Do National Patent Laws Stimulate Domestic Innovation in A Global Patenting Environment?" Review of Economics and Statistics, 89, 436-453.

[80] Romer, P. (1990). "Endogenous Technical Change", Journal of Political Economy, 98, 71-102.

[81] Rossi-Hansberg, E. and M. Wright. (2007). "Establishment Size Dynamics in the Aggregate Economy." American Economic Review, 97, 1639-1666.

[82] Scherer, F. M. (1984). Innovation and Growth: Schumpeterian Perspectives. MIT Press.

[83] Schmalensee, R. (1989). "Inter-industry Studies of Structure and Performance." In Handbook of Industrial Organization, vol. 2, edited by Richard Schmalensee and Robert D. Willig, North-Holland.

[84] Schmutzler, A. (2010). "Is Competition Good for Innovation? A Simple Approach to An Unresolved Question." Foundations and Trends in Microeconomic Analysis, 5, 355-428.

[85] Segerstrom, P., Anant, T., and Dinopoulos, E. (1990). "A Schumpeterian Model of the Product Cycle", American Economic Review, 88, 1077-1092.

[86] Simon, H. and C. Bonini. (1958) "The Size Distribution of Business Firms", American Economic Review, 48, 607-17.

[87] Stanley, M., S. Buldyrev, S. Havlin, R. Mantegna, M. Salinger, and E. Stanley. (1995). "Zipf Plots and the Size Distribution of Firms", Economic Letters 49, 453-57. 
[88] Syverson, C. (2011). "What Determines Productivity", Journal of Economic Literature 49, 326-365.

[89] Tirole, J. (1988). The Theory of Industrial Organization, MIT Press.

[90] Tushman, M. L. and P. Anderson. (1986). Technological Discontinuities and Organizational Environments." Administrative Science Quarterly, 31, 439-465.

[91] Vandenbussche, J., P. Aghion, and C. Meghir. (2006). "Growth, Distance to Frontier, and Composition of Human Capital." Journal of Economic Growth, 11, 97-127.

[92] Vives, X. (2008). "Innovation and Competitive Pressure." Journal of Industrial Economics, 56, 419-469.

[93] Weil, D. (2012). Economics Growth, Prentice Hall. 